Please do not remove this page

RMIT

UNIVERSITY

\title{
Low-order circulating current suppression of PWM-based modular multilevel converters using DC-link voltage compensation
}

Sun, Yichao; Teixeira, Carlos; Holmes, Grahame; McGrath, Brendan; Zhao, Jianfeng

https://researchrepository.rmit.edu.au/esploro/outputs/9921858836001341/filesAndLinks?institution=61RMIT_INST\&index=null

Sun, Y., Teixeira, C., Holmes, G., McGrath, B., \& Zhao, J. (2018). Low-order circulating current suppression of PWM-based modular multilevel converters using DC-link voltage compensation. IEEE Transactions on Power Electronics, 33(1), 210-225. https://doi.org/10.1109/TPEL.2017.2670369

Document Version: Accepted Manuscript

Published Version: https://doi.org/10.1109/TPEL.2017.2670369

Repository homepage: https://researchrepository.rmit.edu.au

(C) 2017 IEEE. Personal use is permitted, but republication/redistribution requires IEEE permission.

Downloaded On 2023/04/26 19:50:25 +1000 
Thank you for downloading this document from the RMIT Research Repository.

The RMIT Research Repository is an open access database showcasing the research outputs of RMIT University researchers.

RMIT Research Repository: http://researchbank.rmit.edu.au/

\section{Citation:}

Sun, Y, Teixeira, C, Holmes, G, McGrath, B and Zhao, J 2018, 'Low-order circulating current suppression of PWM-based modular multilevel converters using DC-link voltage compensation', IEEE Transactions on Power Electronics, vol. 33, no. 1, pp. 210-225.

\section{See this record in the RMIT Research Repository at:}

https://researchbank.rmit.edu.au/view/rmit:45554

Version: Accepted Manuscript

\section{Copyright Statement:}

(C) C 2017 IEEE. Personal use is permitted, but republication/redistribution requires IEEE permission.

\section{Link to Published Version:}

https://dx.doi.org/10.1109/TPEL.2017.2670369 


\title{
Low Order Circulating Current Suppression of PWM based Modular Multilevel Converters Using DC-link Voltage Compensation
}

\author{
Yichao Sun, Member, IEEE, Carlos Alberto Teixeira, Member, IEEE, Donald Grahame Holmes, Fellow, IEEE, \\ Brendan Peter McGrath, Senior Member, IEEE, Jianfeng Zhao
}

\begin{abstract}
This paper presents a new feed-forward strategy for suppressing low-order harmonic circulating currents in PWM-based modular multilevel converters (MMCs). The approach is based on the new average model approach established in this paper which identifies cross-coupling interactions between the system level and sub-module elements using decomposed dependent sources. As well as improving the damping of the system, the major advantage of this approach is that it maintains the natural DC bus balance property of a PWM modulated MMC by considering the upper and lower arms together (unlike existing feed-forward schemes which treat each MMC arm independently). Moreover, unlike existing direct control resonant strategies, which require careful gain tuning and are highly dependent on the AC system frequency, the proposed approach achieves wideband circulating current ripple suppression without requiring knowledge of the circulating current harmonic frequencies, and needs only a simple PI controller to regulate the circulating current DC component for power balance. This makes it particularly suitable for use in multi-frequency or variable frequency $\mathrm{AC}$ systems. Extensive simulation and matching experimental results, including steady-state and transient responses compared against existing circulating current suppression approaches, validate the effectiveness and benefits of this new feed-forward compensation technique.
\end{abstract}

Index Terms-Circulating current ripple, common- and differential-mode, DC-link voltage compensation, modular multilevel converter (MMC), voltage feed-forward.

\section{INTRODUCTION}

Modular multilevel converters (MMCs) [1] are becoming an attractive topology for higher power applications with their particular arrangement of cascaded half-bridges that do not require individual half-bridge DC sources [2], [3]. Hence they can operate at high DC voltage levels without losing properties such as modularity, redundancy and switching frequency harmonic cancellation. Thus, although the MMC was originally proposed for high voltage direct current transmission (HVDC) systems, it is also a viable choice for insulated gate bipolar transistor (IGBT) applications such as static compensators (STATCOMs), active power filters (APFs), high voltage motor

This work was supported in part by the Australian Research Council Discovery Project DP140102437, and in part by the National Natural Science Foundation of China under Grant 51477030 and 51607037.

Y. Sun is with the School of Electrical Engineering, Southeast University, Nanjing 210096, China (e-mail: yichao.sun1987@gmail.com).

C. A. Teixeira, D. G. Holmes and B. P. McGrath are with the School of Electrical and Computer Engineering, RMIT University, Melbourne, Vic. 3001 Australia (e-mail: carlos.teixeira@rmit.edu.au; brendan.mcgrath@rmit.edu.au; grahame.holmes@rmit.edu.au).

J. Zhao is with the School of Electrical Engineering, Southeast University, Nanjing 210096, China (e-mail: jianfeng_zhao@seu.edu.cn) drives and micro grid energy storage systems [3]-[6].

The major difference between MMCs and conventional converters is the circulating current that flows either between the phase-legs or between each phase-leg and the common DC source. Generally, the only significant component in the circulating current is the DC current supplied or consumed by the DC source, although sometimes additional components are used to achieve specific objectives. For example, inter-arm and inter-phase DC-link voltage balancing can be realized by injecting fundamental frequency positive and negative sequence circulating currents [6], while DC-link common-mode voltage ripples can be eliminated by allowing an appropriate second-order harmonic to flow in the circulating current [7]-[10].

Undesirable circulating current ripple includes both switching frequency and low-order harmonic components. Switching frequency harmonics can be minimized by selecting appropriate sub-module modulation strategies such as arranging the MMC phase-leg arms to modulate their $N$ sub-modules together $(N+1$ modulation) [11], and phase shifting the upperand lower-arm sub-module PWM carriers by zero for even $N$, or $\pi / N$ for odd $N$ [12]-[16]. In contrast, low-order circulating current harmonics are caused by the interaction between each sub-module's modulation reference command and any ripple in its DC-link voltage, and cannot be moderated by the primary PWM process. These harmonics increase in magnitude for either smaller size sub-module DC-link capacitors or smaller arm inductors, and it is commonly accepted that they should be either eliminated or at least suppressed to a small magnitude to reduce the current rating of the converter switching devices [17]-[36].

Existing low-order circulating current suppression techniques can generally be classified into either a direct control or an indirect control approach [17]. Direct control techniques are based on the knowledge that the circulating harmonic currents comprise only even order harmonics with a dominant second-order component [18]-[19]. Since this component presents as a negative sequence harmonic for three-phase systems, it can be eliminated in the rotating reference frame with a negative sequence double frequency $d q$ transformation and two proportional-integral controllers [20]-[21]. However, this method requires a sophisticated sequence extraction procedure for unbalanced three-phase systems [11], [22]-[24], and needs a virtual circuit to be used for single-phase systems [7]. To overcome this limitation, a stationary frame PR resonant controller is commonly used [7], [9], [25]-[26] with separate resonators required for each even harmonic term that is to be eliminated [10], [27]-[29]. Alternatively, a repetitive controller has been proposed to eliminate all even harmonics with a sim- 

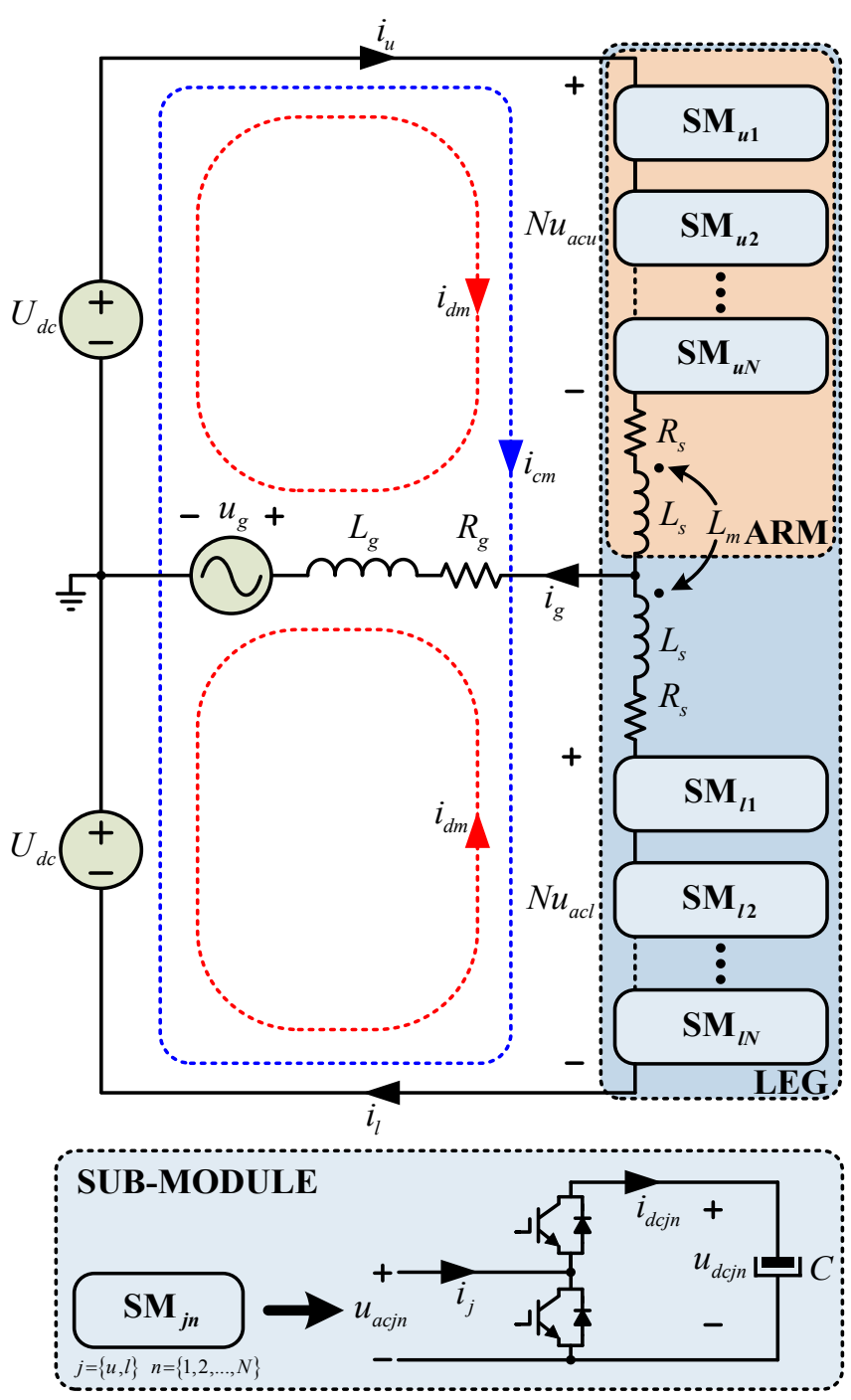

Fig. 1. Circuit diagram of a grid-connected MMC phase-leg.

pler parameter design requirement [30]-[31]. However, all techniques in this family require careful loop design, and need pre-determined frequency information using a full steady state analysis to be effective.

On the other hand, indirect control or feed-forward schemes offer the capability to reduce low-order circulating currents by independently compensating the upper and lower arm modulation references using their respective instantaneous module DC-link voltages [32]. However, this method is only marginally stable with respect to maintaining constant average DC-link voltages and therefore requires an extra inter-arm voltage balance controller to be effective [33]. To overcome this problem, an open-loop control algorithm has been proposed where the measured DC-link voltages are replaced with calculated ones [34], which has been demonstrated to achieve global asymptotic stability both without or with additional current controllers [35]-[36]. However, the performance of this system is highly dependent on the accuracy of the system parameters used for the calculations. Furthermore these calculations become much more complicated or even unachievable when the AC load current contains multiple frequencies.

This paper now presents a new feed-forward approach that considers both arms together and uses the directly measured DC-link voltages, with the objective of retaining the natural DC voltage balancing capability of the MMC. The approach is based on the new average model established in this paper which identifies the coupled relationship between the system level and sub-module elements using decomposed dependent sources. The common-mode offset modulation reference for each sub-module is then augmented using a feed-forward injection to force the system level common-mode dependent source to be only a DC voltage, thus inherently suppressing the circulating current harmonic components. Finally the usual PI closed-loop regulator is added to regulate the DC component of the circulating current to maintain a power flow balance between the DC- and AC-side of the MMC. Results from a realistically sized grid-connected system and a downscaled experimental platform are compared to both the more conventional independent feed-forward scheme and the established resonant controller approach, to confirm the effectiveness of the new strategy.

\section{COMMON- AND DifFERENTIAL-Mode AVERAGE Models OF A MMC PHASE-LEG}

Fig. 1 illustrates one phase-leg of a MMC, consisting of two arms each made up of $N$ series connected sub-modules, where each sub-module is typically a half-bridge topology made up from two IGBTs/diodes and an energy storage DC-link capacitor. The central point of the coupling-inductor connects to the AC grid through its source impedance while two outer phase-leg DC bus terminals are connected to a centre tapped DC source of magnitude $2 U_{d c}$.

Note that the switching harmonics are neglected in the following analysis under the assumption that the switching frequency is well away from the fundamental output frequency and does not affect the average output voltage produced by each sub-module.

\section{A. System Level Average Models}

Applying Kirchhoff's Voltage Law as shown in Fig. 1, the upper- and lower-loop can be analytically defined as

$$
\begin{aligned}
& U_{d c}=N u_{a c u}+R_{s} i_{u}+L_{s} \frac{d i_{u}}{d t}+L_{m} \frac{d i_{l}}{d t}+R_{g} i_{g}+L_{g} \frac{d i_{g}}{d t}+u_{g} \\
& U_{d c}=N u_{a c l}+R_{s} i_{l}+L_{s} \frac{d i_{l}}{d t}+L_{m} \frac{d i_{u}}{d t}-\left(R_{g} i_{g}+L_{g} \frac{d i_{g}}{d t}+u_{g}\right)
\end{aligned}
$$

where $U_{d c}$ and $u_{g}$ are the DC and AC grid voltages, $i_{u}, i_{l}$ and $i_{g}$ are the upper-arm, lower-arm and AC grid currents, $L_{s}, L_{m}$ and $R_{s}$ are the self- and mutual-inductance of the coupling-inductor and its internal resistance, $L_{g}$ and $R_{g}$ are the AC source inductance and resistance, $N$ is the number of sub-modules within each arm, and $u_{a c u}$ and $u_{a c l}$ are the identical (fundamental) output voltage of each sub-module in the upper and lower arms respectively.

The relationship between the $\mathrm{AC}$ grid current and the arm currents is then developed using Kirchhoff's Current Law as

$$
i_{g}=i_{u}-i_{l}
$$

Next, the upper- and lower-arm sub-module voltages and currents in (1)-(3) can be expressed as the following combinations of common-mode $(\mathrm{cm})$ and differential-mode $(\mathrm{dm})$ quan- 

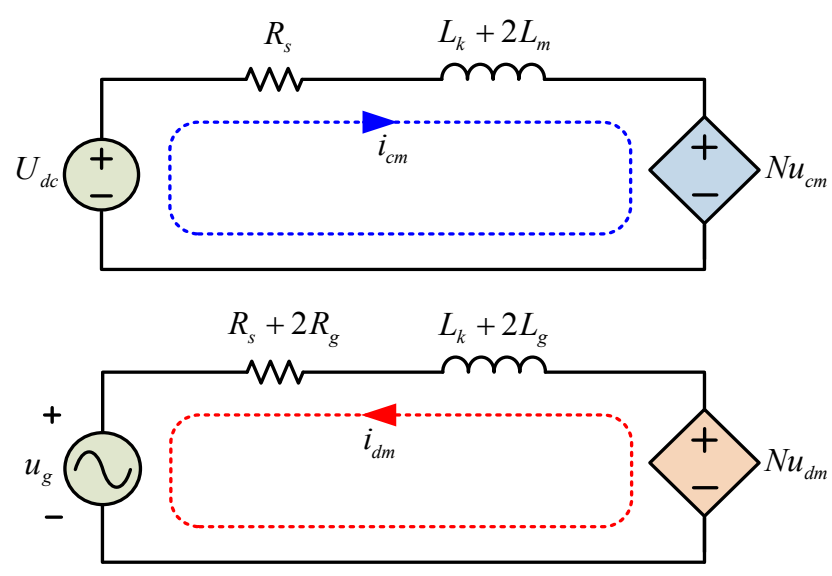

Fig. 2. System level common- and differential-mode average models of a MMC phase-leg.

tities:

$$
\begin{aligned}
i_{u} & =i_{c m}+i_{d m} & & i_{l}=i_{c m}-i_{d m} \\
u_{a c u} & =u_{c m}-u_{d m} & & u_{a c l}=u_{c m}+u_{d m}
\end{aligned}
$$

It should be noted that while these common- and differential-mode quantities are not directly measurable, they considerably simplify the following analysis by transforming the MMC into separate AC and DC systems [6].

System level common- and differential-mode average models can now be derived by adding and subtracting (1) and (2) and substituting from (3)-(5), to give

$$
\begin{gathered}
N u_{c m}=U_{d c}-R_{s} i_{c m}-\left(L_{k}+2 L_{m}\right) \frac{d i_{c m}}{d t} \\
N u_{d m}=\left(R_{s}+2 R_{g}\right) i_{d m}+\left(L_{k}+2 L_{g}\right) \frac{d i_{d m}}{d t}+u_{g}
\end{gathered}
$$

where $L_{k}=L_{s}-L_{m}$ is the arm leakage inductance which is relatively small in practice (note that $L_{m}=0$ equates to uncoupled inductors in each arm, which does not change the analysis).

Fig. 2 shows these system level MMC average models where the DC and AC systems act independently based on commonand differential-mode quantities. Note that the common-mode current, $i_{c m}$, is conventionally called the circulating current in the literature as it only flows between the phase-leg and the DC source (or between the phase-legs for a three-phase system).

\section{B. Sub-module Average Models}

Since they use the same modulation references, the sub-modules within each arm can be assumed on average to operate identically, with their currents and voltages defined by

$$
\begin{aligned}
& i_{d c j 1}=i_{d c j 2}=\ldots=i_{d c j n}=\ldots=i_{d c j N}=i_{d c j} \\
& u_{d c j 1}=u_{d c j 2}=\ldots=u_{d c j n}=\ldots=u_{d c j N}=u_{d c j}
\end{aligned}
$$

where $i_{d c j n}$ and $u_{d c j n}$ represent the DC-link current and voltage of the $n$-th sub-module and the subscript $j=\{u, l\}$ denotes the upper- or lower-arm respectively.

With this simplification the sub-module operation can be defined using the two differential equations of

$$
\begin{aligned}
& i_{d c u}=C \frac{d u_{d c u}}{d t} \\
& i_{d c l}=C \frac{d u_{d c l}}{d t}
\end{aligned}
$$

where $C$ is the DC-link capacitor for each sub-module.

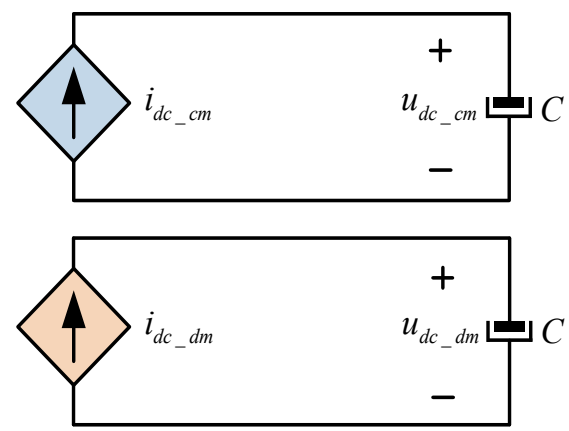

Fig. 3. Sub-module level common- and differential-mode average models of a MMC phase-leg.

Following the concept of the system level average model, the sub-module voltages and currents can also be expressed using common-mode and differential-mode quantities as

$$
\begin{array}{cc}
i_{d c u}=i_{d c_{-} c m}-i_{d c_{-} d m} & i_{d c l}=i_{d c_{-} c m}+i_{d c_{-} d m} \\
u_{d c u}=u_{d c_{-} c m}-u_{d c_{-} d m} & u_{d c l}=u_{d c_{-} c m}+u_{d c_{-} d m}
\end{array}
$$

Adding and subtracting (10) and (11) and then substituting from (12) and (13) gives

$$
\begin{gathered}
i_{d c_{-} c m}=C \frac{d u_{d c_{-} c m}}{d t} \\
i_{d c_{-} d m}=C \frac{d u_{d c_{-} d m}}{d t}
\end{gathered}
$$

Fig. 3 shows these sub-module average models.

\section{Decomposition of the Dependent Sources}

The MMC sub-module modulation reference waveform is typically a combination of a common-mode reference, $m_{c m}$, and a differential-mode reference, $m_{d m}$, so that

$$
m_{u}=m_{c m}-m_{d m} \quad m_{l}=m_{c m}+m_{d m}
$$

where $m_{u}$ and $m_{l}$ are the modulation commands of sub-modules in the upper and lower arms respectively. From fundamental half-bridge modulation theory [37] the conventional common-mode modulation reference is a fixed $50 \%$ value while the differential-mode reference is a sinusoidal waveform, given by

$$
\begin{gathered}
m_{c m}=0.5 \\
m_{d m}=0.5 \mathrm{M} \cos \omega_{o} t
\end{gathered}
$$

where $M$ is the differential-mode modulation depth of each sub-module $(0 \leq M \leq 1)$ and $\omega_{o}$ is the AC system fundamental frequency.

For each sub-module, their AC output and DC-side voltages and currents are linked through their modulation references by

$$
\begin{array}{cc}
u_{a c u}=m_{u} u_{d c u} & u_{a c l}=m_{l} u_{d c l} \\
i_{d c u}=m_{u} i_{u} & i_{d c l}=m_{l} i_{l}
\end{array}
$$

Hence the dependent sources in Figs. 2 and 3 can be revised by substituting (4), (5), (12) and (13) into (19) and (20), to give

$$
\begin{gathered}
N u_{c m}=N m_{c m} u_{d c_{-} c m}+N m_{d m} u_{d c_{-} d m} \\
N u_{d m}=N m_{c m} u_{d c_{-} d m}+N m_{d m} u_{d c_{-} c m} \\
i_{d_{c_{-}} c m}=m_{c m} i_{c m}-m_{d m} i_{d m} \\
i_{d c_{-} d m}=m_{d m} i_{c m}-m_{c m} i_{d m}
\end{gathered}
$$

Fig. 4 shows the overall average MMC model achieved with these decomposed dependent sources. This model can now be used to identify how the system level and sub-module common- 
and differential-mode voltages and currents cross-couple through the sub-module modulation processes to produce harmonic circulating currents.

For example, looking at the system level common-mode circuit, the circulating current $i_{c m}$ is determined by the voltage difference between the DC source $U_{d c}$ and the two series dependent sources, across the common-mode RL impedance. The magnitudes of these dependent sources are determined by the product of the differential- and common-mode modulation references and the sub-module differential- and common-mode DC-link capacitor voltages as defined by (21). Finally, these voltages are determined by the injected current created by the product of the modulation references and the system level differential- and common-mode currents, as defined by (23) and (24).

The magnitude of the $m_{d m} i_{d m}$ current source in the common-mode sub-module section of Fig. 4 has a large second harmonic term since it is the product of two fundamental sinusoid components. Hence the common-mode sub-module voltage $u_{d c_{c} c m}$ will develop a significant second harmonic ripple via (14), which in turn will reflect back into the system level common-mode circuit through the dependent source $\mathrm{Nm}_{\mathrm{c} \text { - }}$ ${ }_{m} u_{d c_{-} \mathrm{cm}}$. Similar cross-coupling interactions will also cause a second harmonic term in the system level common-mode dependent source $N m_{d m} u_{d c d m}$. Since the common-mode RL impedance is typically designed as small as possible, these two dependent sources will produce a significant second order harmonic component in the circulating current $i_{c m}$.

With this understanding, a second order resonant controller is commonly used to reduce this second order harmonic current component. Alternatively, all of the circulating harmonic currents can be reduced without requiring a detailed steady state analysis to identify each possible harmonic frequency, by simply forcing the common-mode dependent voltage sources to be only a DC voltage. This is the approach now presented in this paper.

\section{PI+C HARMONIC CIRCULATING CURRENT COMPENSATION}

\section{A. Augmenting the Sub-module Common-mode Modulation Reference to Suppress Harmonic Circulating Current}

To suppress the common-mode circulating current, the sum of the system level common-mode dependent sources in Fig. 4 must essentially be equal to $U_{d c}$ (assuming $R_{s}$ is small). Using the ideal common-mode modulation reference of $m_{c m}=0.5$ (17) as a starting point, this relationship can be expressed as

$$
N m_{c m_{-} c} u_{d c_{-} c m}+N m_{d m} u_{d c_{-} d m}=2 m_{c m} U_{d c}
$$

where $m_{c m}{ }_{C}$ is the augmented common-mode modulation reference that is modified to achieve this objective - note that the differential-mode modulation command $m_{d m}$ cannot be used for this role because it determines the MMC AC output voltage as per (18). Rearranging (25) then gives

$$
m_{c m_{-} C}=\frac{2 m_{c m} U_{d c} / N-m_{d m} u_{d c_{-} d m}}{u_{d c \text { cm }}}
$$

If the assumptions of (8) and (9) are satisfied, only two sub-module DC-link voltages need to be measured to implement (26), i.e. one in the upper-arm and another in the lower-arm. The sub-module DC-link common- and differential-mode voltages can then be obtained using

$$
\left\{\begin{array}{l}
u_{d c_{-} c m}=\left(u_{d c l 1}+u_{d c u 1}\right) / 2 \\
u_{d c_{-} d m}=\left(u_{d c l 1}-u_{d c u 1}\right) / 2
\end{array}\right.
$$

Alternatively, if the assumptions of (8) and (9) are violated by unmatched sub-module capacitors for example, the average sub-module DC-link common- and differential-mode voltages can be determined by additional measurements according to

$$
\left\{\begin{array}{l}
u_{d c_{-} c m}=\sum_{n=1}^{N}\left(u_{d c l n}+u_{d c u n}\right) / 2 N \\
u_{d c_{-} d m}=\sum_{n=1}^{N}\left(u_{d c l n}-u_{d c u n}\right) / 2 N
\end{array}\right.
$$

In either case, the augmented common-mode modulation expression of (26) provides a feed-forward compensation capability that will essentially eliminate circulating current harmonic components without requiring a closed-loop controller.
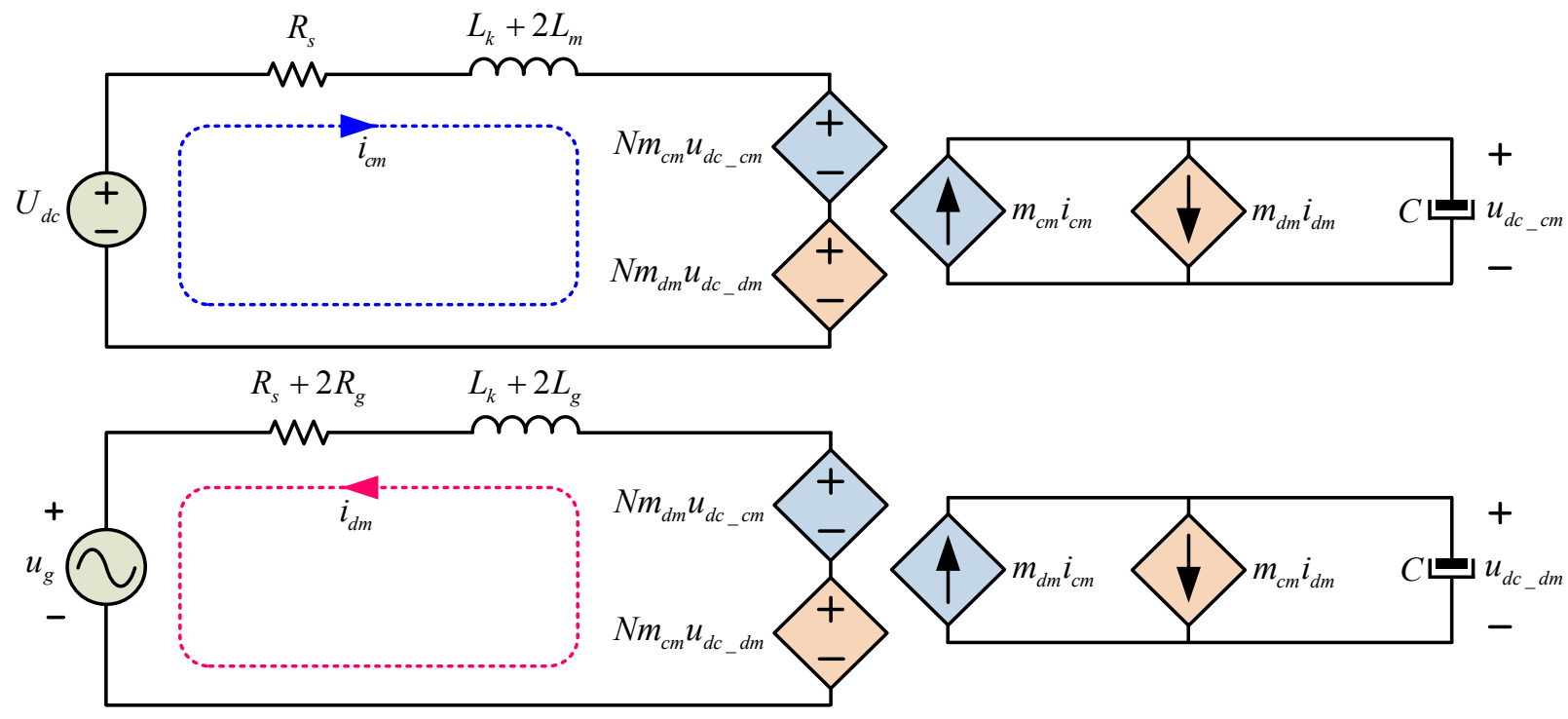

Fig. 4. Overall common- and differential-mode average models of a MMC phase-leg with dependent sources linking the system and sub-module levels. 


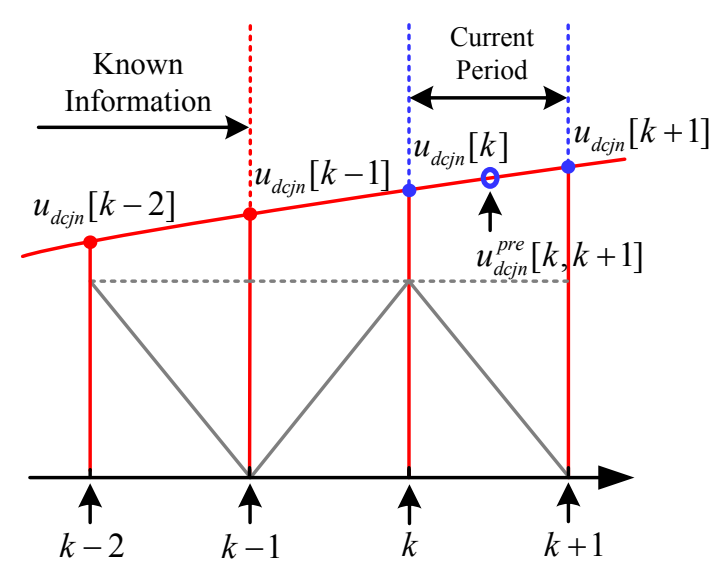

Fig. 5. Sub-module DC-link voltage prediction principle.

\section{B. Sub-module DC-link Voltage Prediction}

In practice the feed-forward suppression of the circulating current harmonics will not be ideal because of regular sampling and measurement delays that exist in the physical system. In other words, the measured sub-module DC-link voltages used for the augmentation calculation will lag the real voltages that exist at the sub-module switching instances. However, this mismatch can be minimized by forward predicting the voltages over each half-carrier switching interval. For example, at the half carrier modulation sampling point $[k]$ shown in Fig. 5, only the sub-module voltages at sampling points $[k-1, k-2, \ldots]$ are known. But using the simple linear extrapolation of

$$
u[k]=2 u[k-1]-u[k-2]
$$

the average sub-module voltage between the sampling points $[k]$ and $[k+1]$ can be readily predicted as

$$
u_{d c j n}^{p r e}[k, k+1]=u_{d c i n}^{p r e}[k-1]+\frac{3}{2}\left(u_{d c j n}^{p r e}[k-1]-u_{d c j n}^{p r e}[k-2]\right)
$$

Substituting (30) into (26) gives an improved augmented common-mode modulation reference for each sub-module of

$$
m_{c m_{-} C}^{p r e}=\frac{2 m_{c m} U_{d c} / N-m_{d m} u_{d c_{-} d m}^{p r e}}{u_{d c_{-} c m}^{p r e}}
$$

\section{Maintaining Power Balance Between the DC and AC Sys- tems Using PI Regulators}

Steady-state operation of a MMC requires that the DC source power and the AC grid power are always matched, since otherwise the sub-module DC-link voltages will deviate away from their required DC average magnitude of $2 U_{d c} / N$. In practice, since the $\mathrm{AC}$ system power consumption is variable under different operating conditions, the power match is best achieved by modifying the ideal common-mode modulation reference of (17) to maintain the sub-module DC average common-mode voltages at $2 U_{d c} / N$, according to

$$
m_{c m}^{\prime}=0.5+\Delta M
$$

$\Delta M$ is calculated using dual closed-loop inner current/outer voltage PI regulators of

$$
\begin{gathered}
\Delta M=K_{i_{-} c m}\left(1+\frac{1}{\tau_{i_{-} c m} s}\right)\left(i_{c m}-i_{c m}^{*}\right) \\
i_{c m}^{*}=K_{u}\left(1+\frac{1}{\tau_{u} s}\right)\left(\frac{2 U_{d c}}{N}-\operatorname{LPF}\left\{u_{d c_{-} c m}\right\}\right)
\end{gathered}
$$

where $k_{i_{-} \mathrm{cm}}$ and $\tau_{i_{-} \mathrm{cm}}$ are the current controller proportional gain and integral reset time, $k_{u}$ and $\tau_{u}$ are the voltage controller proportional gain and integral reset time respectively, and $i_{c m}^{*}$ is the common-mode current reference produced by the outer-loop voltage regulator. Note that the reversed current error logic in (33) comes about because the defined reference direction for $i_{c m}$ in Fig. 1 means that an increase in $\Delta M$ will cause a decrease in the magnitude of $i_{c m}$. Note also that the DC-link common-mode voltage used in (34) must be smoothed by a low pass filter (LPF) to avoid injecting any harmonic ripple components into the common-mode current reference $i_{\mathrm{cm}}{ }_{\mathrm{m}}$.

The final augmented common-mode modulation reference now becomes, from (31) and (32),

$$
m_{c m_{-} C}^{\prime}=\frac{2 m_{c m}^{\prime} U_{d c} / N-m_{d m} u_{d c_{-} d m}^{p r e}}{u_{d c_{-} c m}^{p r e}}
$$

Fig. 6 shows the overall new feed-forward control structure based on these concepts, with the classical PI dual-loop controller for DC voltage regulation, and harmonic circulating current suppression implemented using augmented common-mode modulation. Note that the plant block $G_{c m p}(s)$ shown in Fig. 6 is the reciprocal of the common-mode system impedance $R_{s}+s\left(L_{k}+2 L_{m}\right)$.

Note: Although the PI regulators are primarily used to maintain power balance (i.e. the average value of $u_{d c_{c} \mathrm{~cm}}$ ), they also provide a finite loop gain for low-order harmonics. Hence they help to mitigate these harmonic currents if they have not been fully eliminated by the feed forward compensation because of practical second order effects.

\section{INTER-ARM DC Voltage NATURAL BALANCE ANALYSIS}

The inner-arm and inter-arm DC voltages of a MMC are known to naturally balance [38] when certain switching frequencies are avoided [14] for PSC-PWM modulation with

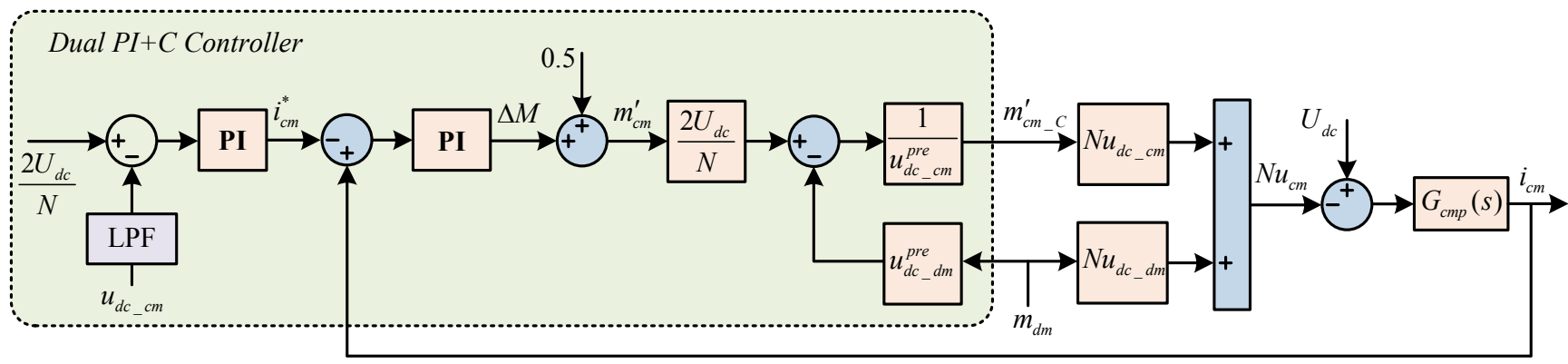

Fig. 6. Overall compensated MMC control with closed-loop DC voltage regulator and harmonic ripple suppression using common-mode augmentation. 
fixed modulation references. So, given that inner-arm natural DC bus voltage balance is guaranteed when exactly the same modulation references are used for all modules, it is important to now determine how the inter-arm natural balancing may be influenced when incorporating circulating current suppression techniques.

The overall system established in Fig. 4 is time varying due to the presence of sinusoidal differential-mode modulation references in the coefficients. This makes a complete stability analysis difficult. Nevertheless, a simple stability analysis can be achieved by rearranging (6), (7), (21) and (22) to give

$$
\begin{aligned}
& i_{c m}=\frac{1}{\left(L_{k}+2 L_{m}\right)} \int\left[U_{d c}-\left(N m_{c m} u_{d c_{-} c m}+N m_{d m} u_{d c_{-} d m}\right)-R_{s} i_{c m}\right] d t \\
& i_{d m}=\frac{1}{\left(L_{k}+2 L_{g}\right)} \int\left[N m_{c m} u_{d c_{-} d m}+N m_{d m} u_{d c_{-} c m}-u_{g}-\left(R_{s}+2 R_{g}\right) i_{d m}\right] d t
\end{aligned}
$$

and then proceeding with the following analysis sequence.

\section{A. Modulating the MMC Using Fixed References}

Taking (17) and (18) as a starting point, the common- and differential-mode modulation references are fixed so that they have no impact on the system dynamics. Then, assuming an initial inter-arm voltage unbalance is present in the differential-mode DC-link voltage $u_{d c-d m}$ (Fig. 7(a)), the common-mode current $i_{c m}$ will decrease and the differential-mode current $i_{d m}$ will increase respectively via (36) and (37) (Fig. 7(b)). Taking this effect back into (24), both of these two current variations will help drive the voltage $u_{d c \_d m}$ back to its steady state (i.e. $0 \mathrm{~V})$. A similar phenomenon can be identified for the common-mode voltage $u_{d c_{-} c m}$. Hence the averaged DC-link voltages $u_{d c_{-} c m}$ and $u_{d c_{-} d m}$ can be seen to self-regulate to their steady state values (i.e. naturally balanced) driven by the currents $i_{c m}$ and $i_{d m}$.

Note that the current responses depend solely on their respective system resistance and inductance as per (36) and (37). While the small inductance ensures a fast current dynamic which guarantees the self-regulation process, the small re-

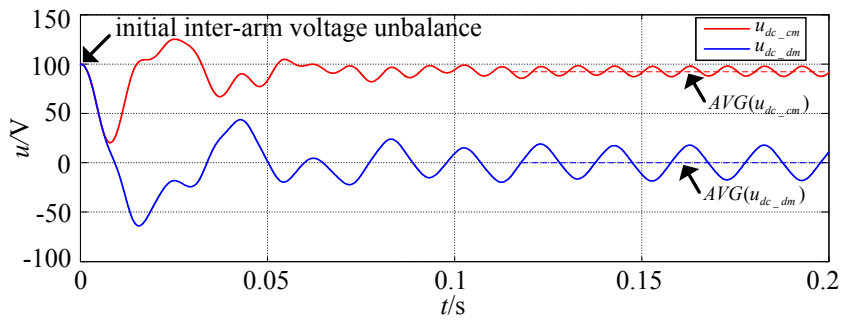

(a)

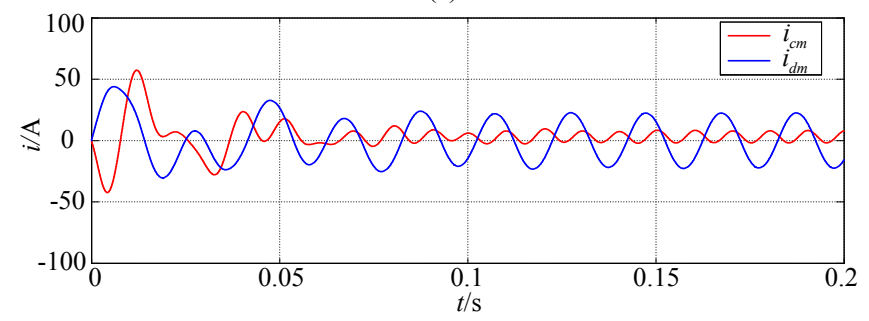

(b)

Fig. 7. DC voltage self-regulation process with fixed modulation references. $\left(R_{s}=0.2 \Omega, R_{g}=0.5 \Omega, U_{d d} / N=100 \mathrm{~V}\right)$ (a) DC-link common- and differential-mode voltages. (b) Common- and differential-mode currents. sistance leads to an underdamped system which may require several cycles to settle down. Moreover, a small averaged common-mode $\mathrm{DC}$ voltage error with respect to expected value $U_{d c} / N$, is inevitable with this modulation as shown in Fig. 7(a), since power balance is not considered in this first stage of the analysis (i.e. fixed modulation references).

\section{B. Incorporating the Proposed Feed-forward Compensation}

When the common-mode current is augmented through the proposed feed-forward scheme, substituting (35) into (36) gives

$$
i_{c m}=\frac{1}{\left(L_{k}+2 L_{m}\right)} \int\left[-2 U_{d c} \Delta M-R_{s} i_{c m}\right] d t
$$

From (38), the common-mode current is designed to be responsible for controlling the averaged DC-link common-mode voltage $u_{d c_{c} c m}$ (i.e. power balance) by adjusting $\Delta M$, which implies that the common-mode current will no longer respond to changes of $u_{d c} d m$ as shown in Fig. 8(a). Nevertheless, DC bus voltage self-regulation will still be achieved by the action of the differential-mode current $i_{d m}$ as shown in Fig. 8(b). The strategy also provides the additional benefits of an improved power balance and quicker system damping, as can be seen by comparing Fig. 8 against Fig. 7.

For cases where $R_{g}$ or $L_{g}$ is extremely large (i.e., the $\mathrm{AC}$ system is disconnected), the differential-mode current becomes zero, which makes self-regulation unachievable. Hence the proposed feed-forward scheme should be temporarily discontinued in this scenario so that the common-mode current can return to the role of the self-regulation. However, this constraint is quite reasonable given that there is no need for harmonic circulation current control when the MMC is operating in standby.

\section{Conventional Independent Feed-forward Compensation of the Upper and Lower Arms}

Feed-forward of the upper and lower arm output voltages independently as proposed in [32] effectively compensates both the common- and differential-mode currents simultaneously. Hence both of the system level current components, $i_{c m}$ and $i_{d m}$,

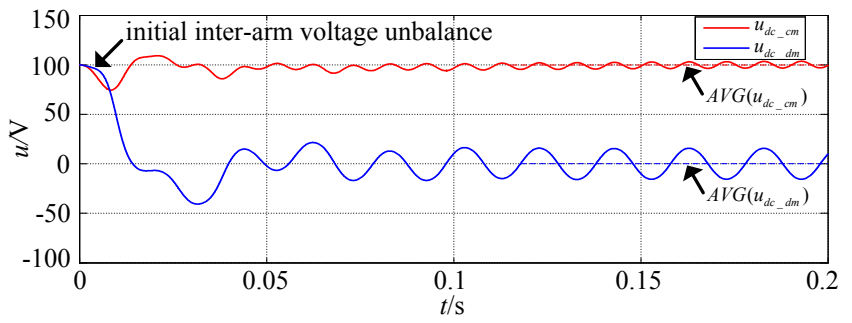

(a)

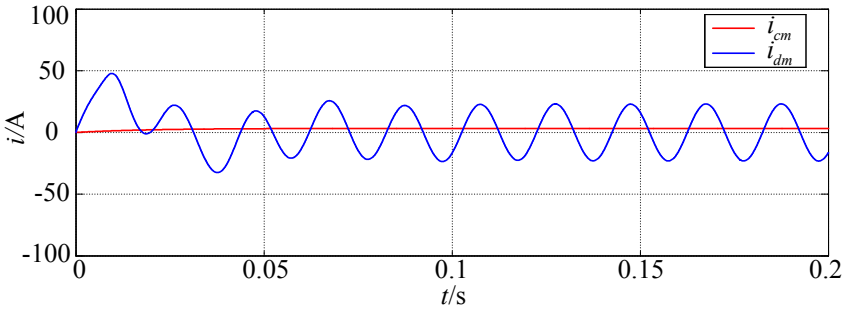

(b)

Fig. 8. DC voltage self-regulation process with the proposed feed-forward compensation. ( $R_{s}=0.2 \Omega, R_{g}=0.5 \Omega$ ) (a) DC-link common- and differential-mode voltages. (b) Common- and differential-mode currents. 


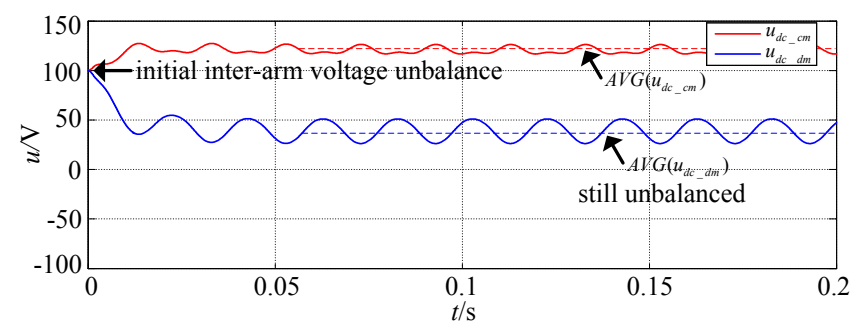

(a)

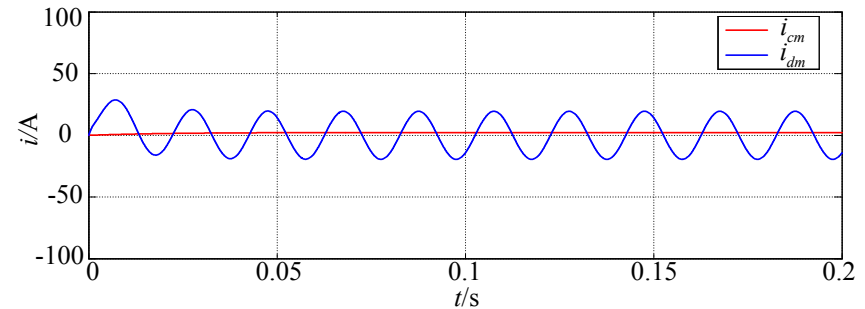

(b)

Fig. 9. DC voltage dynamics if feed-forwarding the upper and lower arms independently [32]. ( $R_{s}=0.2 \Omega, R_{g}=0.5 \Omega$ ) (a) DC-link common- and differential-mode voltages. (b) Common- and differential-mode currents.

are strictly controlled to their designed values, i.e. DC and fundamental AC respectively (Fig. 9(b)), and cannot contribute to the self-regulation process. This leads to unbalanced DC-link voltages as shown in Fig. 9(a), which require additional voltage controllers as presented in [32] to balance these voltages by adding extra components into the circulating current $i_{c m}$. Hence this strategy does not achieve natural balancing of the module DC voltages.

\section{INDUSTRIAL LEVEL SIMULATION RESULTS}

To explore the performance of the proposed new feed-forward compensation strategy, a three-phase MMC converter with eight sub-modules per arm has been simulated using PSIM, with system and controller parameters as detailed in Table I.

Asymmetric regular sampled PSC-PWM [37] with in-phase carriers for the upper and lower arms is used to maximize cancellation of the switching frequency common-mode currents. The gains of the PI common-mode and PR differential-mode current controllers are optimally calculated so as to maximize the system bandwidth, taking into account PWM transport and sampling delays using the principles presented in [39], [40]. The average current reference is regulated by the voltage controller to maintain the sub-module averaged DC-link common-mode voltages at $2 U_{d c} / N$, with its gains set heuristically to achieve a fast yet stable transient response. Note that no additional voltage balance controller has been implemented in all cases shown below, with inner arm voltage balance being automatically achieved through the PSC-PWM modulation process only [38].

\section{A. Natural Balance Capability Compared to Independent Feed-forward Compensation.}

A natural balancing test is performed to show the advantage of the proposed approach compared to independent feed-forward compensation of each MMC arm. As predicted by the previous stability analysis, when independent feed-forward compensation is used, the differential-mode DC-link voltages start to move from zero to a new equilibrium point due to the
TABLE I

SIMULATION SYSTEM CONFIGURATIONS AND PARAMETERS

\begin{tabular}{|c|c|c|}
\hline Description & Symbol & Value \\
\hline \multicolumn{3}{|l|}{ System parameters } \\
\hline DC supply voltage & $U_{d c}$ & $10 \mathrm{kV}$ \\
\hline AC grid voltage (RMS) & $u_{g}$ & $5.77 \mathrm{kV}$ \\
\hline $\mathrm{AC}$ grid frequency & $f_{g}$ & $50 \mathrm{~Hz}$ \\
\hline AC source resistance & $R_{g}$ & $0.5 \Omega$ \\
\hline AC source inductance & $L_{g}$ & $6 \mathrm{mH}$ \\
\hline \multicolumn{3}{|l|}{ Coupling-inductor } \\
\hline Self-inductance & $L_{s}$ & $6 \mathrm{mH}$ \\
\hline Mutual-inductance & $L_{m}$ & $5.7 \mathrm{mH}$ \\
\hline Leakage-inductance & $L_{k}$ & $0.3 \mathrm{mH}$ \\
\hline Individual winding-resistance & $R_{s}$ & $0.2 \Omega$ \\
\hline DC-link capacitor & $C$ & $1100 \mu \mathrm{F}$ \\
\hline Switching frequency & $f_{c}$ & $1 \mathrm{kHz}$ \\
\hline Sampling frequency & $f_{s}$ & $8 \mathrm{kHz}$ \\
\hline Numbers of cells per arm & $N$ & 8 \\
\hline PSC interleaved angle & $\theta$ & $0 \mathrm{rad}$ \\
\hline \multicolumn{3}{|l|}{ Controller parameters } \\
\hline \multicolumn{3}{|l|}{ Common-mode current controller } \\
\hline Proportional gain & $K_{i \_c m}$ & $20.4 \mathrm{~A}^{-1}$ \\
\hline Integral reset time & $\tau_{i \_c m}^{-}$ & $0.0057 \mathrm{~s}$ \\
\hline Resonant reset time & $\tau_{r_{-} c m}^{-}$ & $0.0198 \mathrm{~s}$ \\
\hline \multicolumn{3}{|l|}{ Differential-mode current controller } \\
\hline Proportional gain & $K_{i d m}$ & $20.4 \mathrm{~A}^{-1}$ \\
\hline Resonant reset time & $\tau_{r_{-} d m}$ & $0.0057 \mathrm{~s}$ \\
\hline \multicolumn{3}{|l|}{ Averaged voltage controller } \\
\hline Proportional gain & $K_{u}$ & $0.2 \mathrm{~V}^{-1}$ \\
\hline Integral reset time & $\tau_{u}$ & $0.02 \mathrm{~s}$ \\
\hline
\end{tabular}

marginal stability of this approach, as shown in Fig. 10(c). This in turn gradually distorts the circulating current as shown in Fig. 10(a). In contrast, the proposed direct feed-forward approach maintains the DC voltage natural balance with the influence of differential-mode current during system dynamics, as shown in Fig. 10(b) and Fig. 10(d).

\section{B. Dynamic Performance under Different Operating Condi- tions}

A comparison between the proposed approach and the resonant harmonic regulator method is tested on the three phase MMC under four-quadrant operating conditions. The results are shown in Fig. 11 and Fig. 12, where positive $\mathrm{P}$ means active power is being transferred from the DC system to the AC system, while positive $\mathrm{Q}$ means inductive power injection into the AC system. During each load condition change, the resonant controller creates a small oscillation during resettling (Fig. 11(b)) whereas the proposed method achieves a smooth continuous DC current flow (Fig. 12(b)) by strictly regulating the voltage $N u_{c m}$ to DC. Both methods achieve natural balancing as shown in Fig. 11(a) and Fig. 12(a), because the differential-mode current continues to participate in regulating the $\mathrm{DC}$ voltages during system transients.

\section{Dynamic Performance under Unbalanced AC Grid Con- ditions}

The three phase MMC system is now further tested under unbalanced AC grid conditions to demonstrate the per phase control capability of the new strategy. As shown in Fig. 13, the proposed feed-forward scheme is enabled at $\mathrm{t}=0.4 \mathrm{~s}$, a $10 \%$ negative sequence $\mathrm{AC}$ grid voltage is introduced at $\mathrm{t}=0.6 \mathrm{~s}$, and then a $60 \%$ increase in current is drawn from phase $\mathrm{A}$ at $\mathrm{t}=0.8$ to simulate an unbalanced local load situation. From Fig. 13(b), it can be seen that the three phase currents are successfully con- 


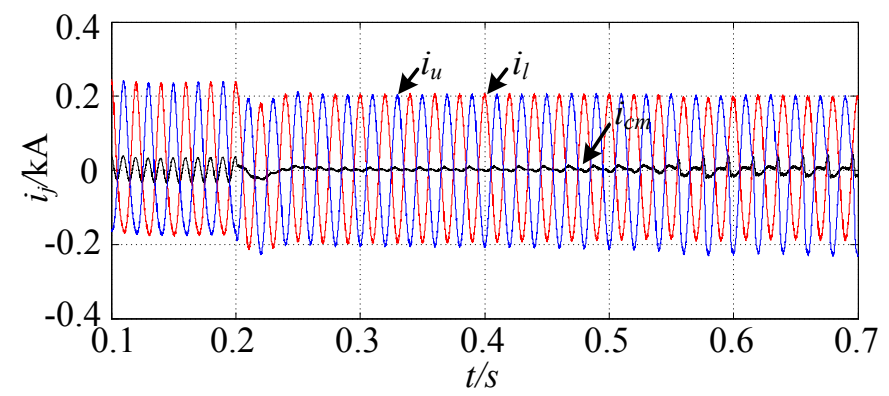

(a)

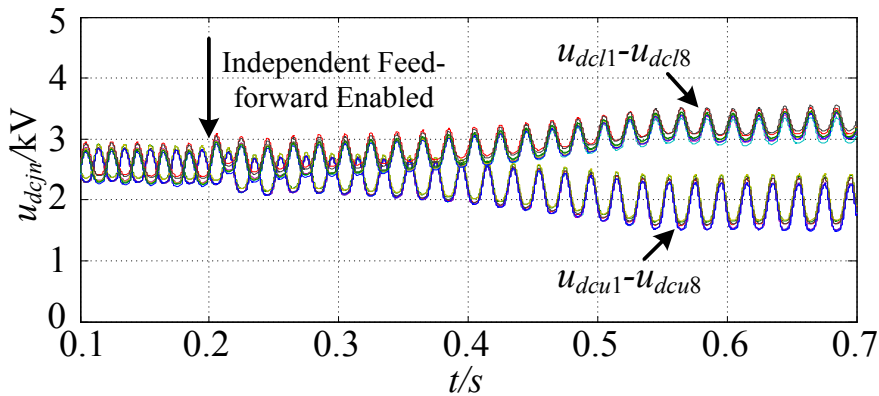

(c)

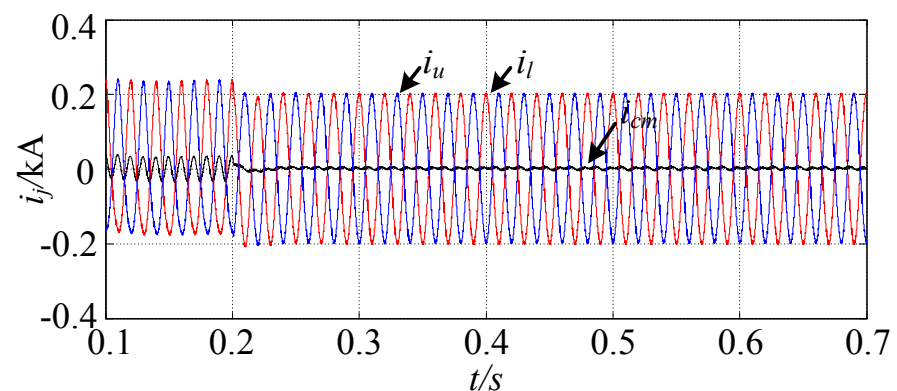

(b)

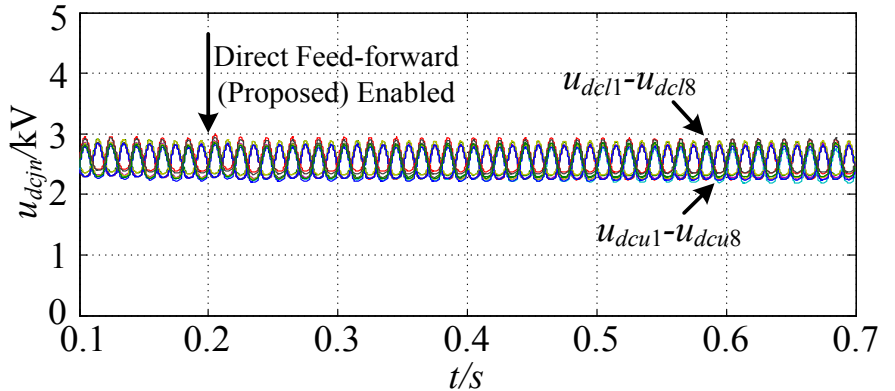

(d)

Fig. 10. Comparison between the proposed feedforward controller (PI+C) and the conventional independent feed-forward scheme: (a) Arm and common-mode currents using [32], (b) Arm currents and common-mode current using the proposed scheme, (c) DC-link voltages using [32], (d) DC-link voltages using the proposed scheme.

trolled to their designed references regardless of whether the AC grid system is balanced or not. The three circulating currents in Fig. 13(a), however, change separately under different $\mathrm{AC}$ system conditions to enable the active power balance in each phase.

Note that there is a small periodic error existing in the common-mode current with this compensation strategy. This is caused by two reasons. One is the non-strictly accurate compensation as mentioned in section III.B with a relatively small switching frequency, and another is the small DC-link voltage ripple mismatch among sub-modules due to the phase shifted carriers. However, this error could be minimized by increasing the sub-module switching frequency if necessary.

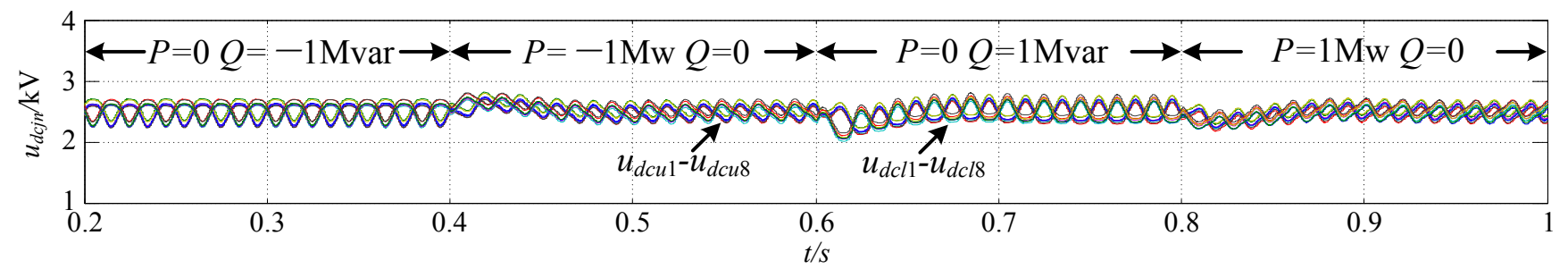

(a)

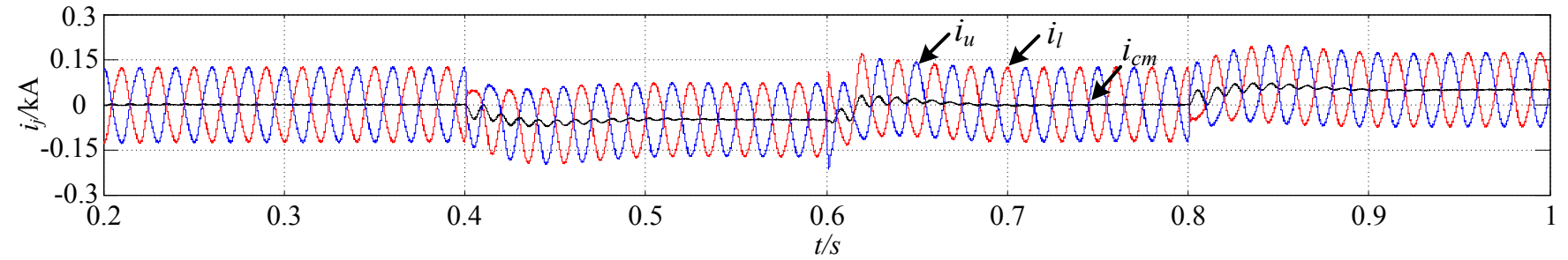

(b)

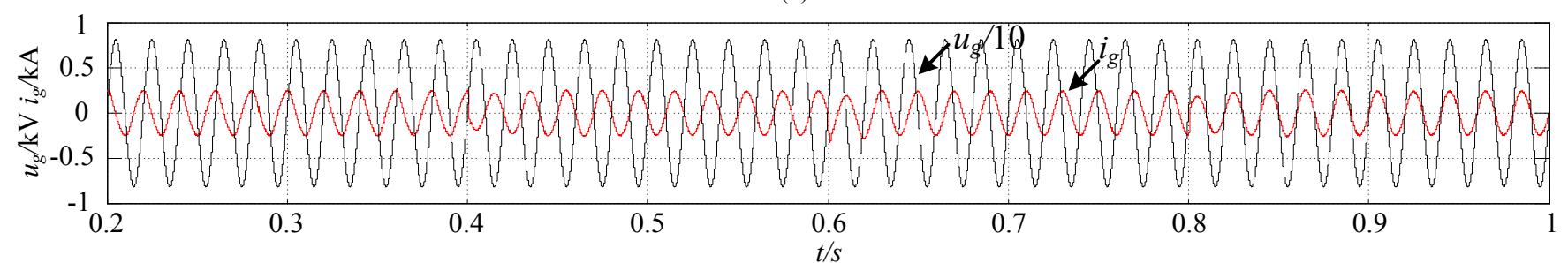

(c)

Fig. 11. Performance of the resonant controller (PI+Res2) under different operating conditions: (a) DC-link voltages, (b) Arm currents and common-mode current, (c) AC grid voltage and current. 


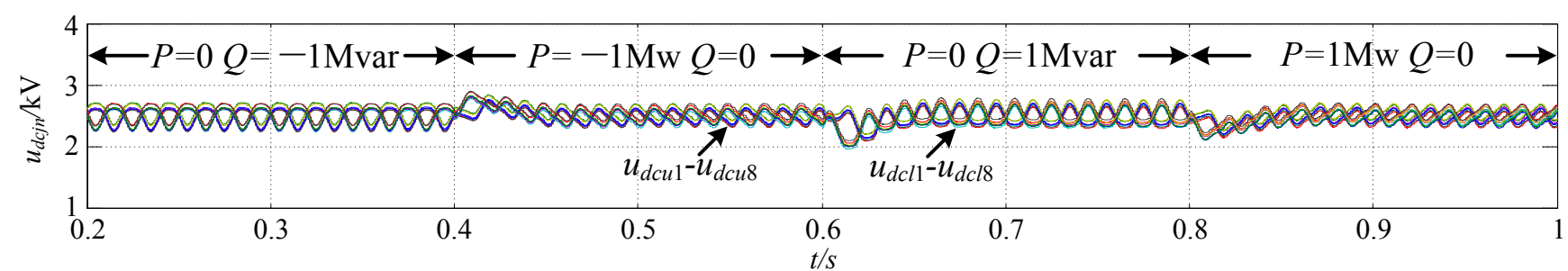

(a)

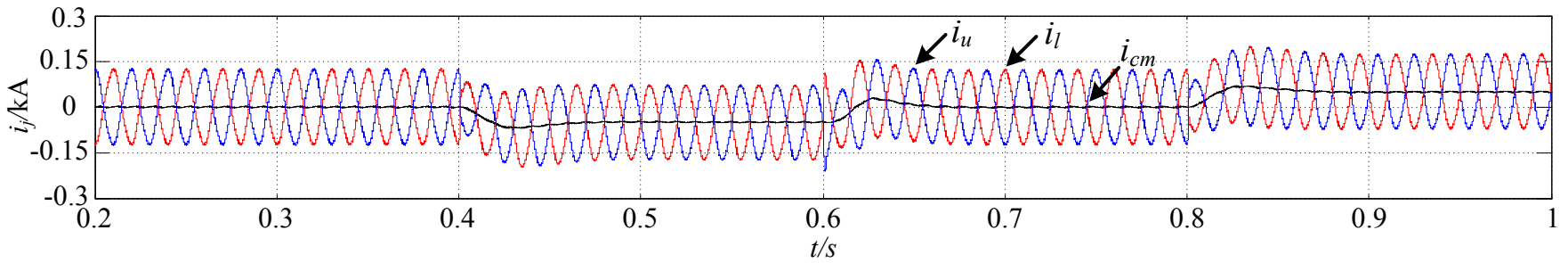

(b)

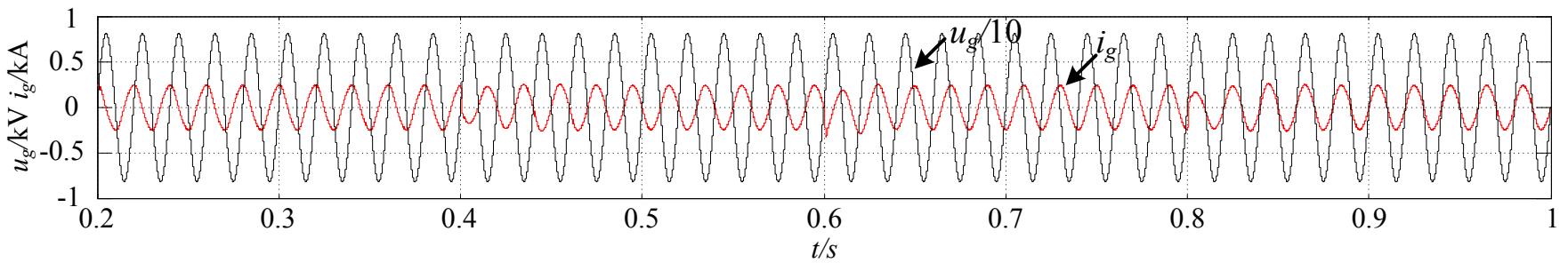

(c)

Fig. 12. Performance of the proposed feedforward controller (PI+C) under different operating conditions: (a) DC-link voltages, (b) Arm currents and common-mode current, (c) AC grid voltage and current.

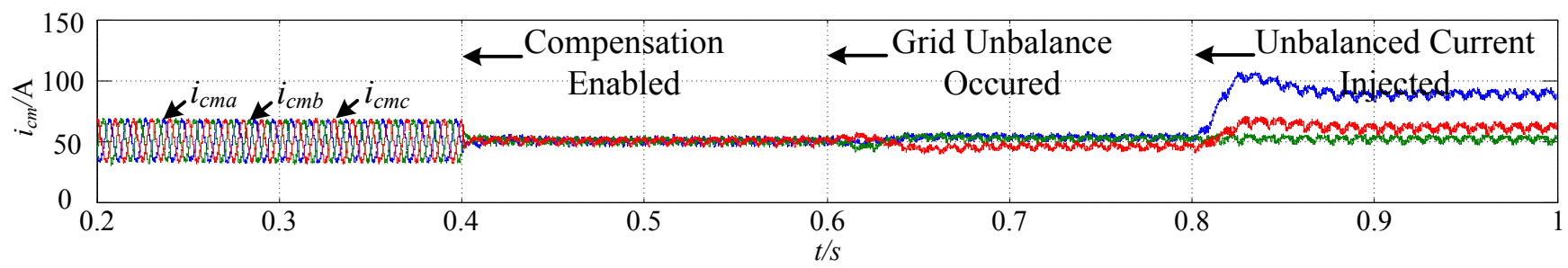

(a)

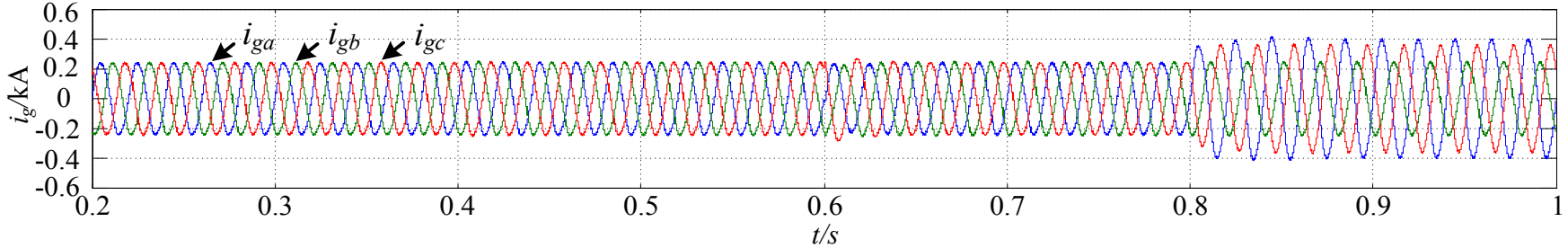

(b)

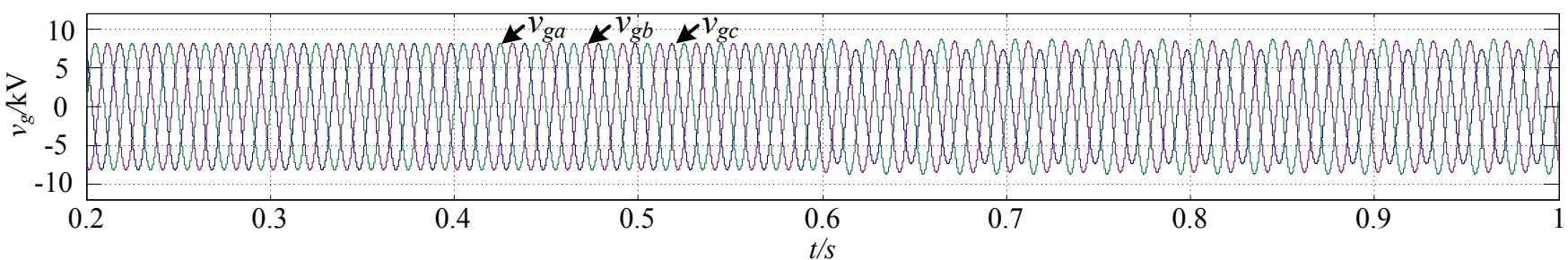

(c)

Fig. 13. Performance of the proposed feedforward controller (PI+C) under unbalanced AC grid conditions: (a) Common-mode currents, (b) AC system currents (double differential-mode current), (c) AC system grid voltage.

\section{LABORATORY EXPERIMENTAL RESULTS WITH SIMULATION REFERENCES}

\section{A. Prototype and Controller Parameters}

The performance of the proposed feed-forward compensation technique is further confirmed using simulation and matching experimental investigations on a single phase-leg MMC platform as shown in Fig. 14 with parameters as listed in Table II. The MMC arm is made up of two sub-modules, with 
the common DC supply provided by two series connected DC power sources. For simplicity, the AC system is replaced by a passive RL load and the proposed approach is executed using a central controller using a low cost TMS320F2812 processor. The coupled-inductors and sub-module DC-link capacitors were sized with relatively small p.u. magnitudes to produce higher levels of circulating current harmonics in the converter. For these tests, the AC system was commanded by an open loop modulation reference, which means that natural balance is guaranteed for both the proposed feed-forward and the resonant compensation approach.

\section{B. Steady-State Performance}

Fig. 15 presents steady-state simulation and experimental waveforms of the upper-/lower-arm currents and common-mode circulating current for the MMC system operating under four different controller types: dual PI controller without feed-forward DC-link compensation (Figs. 15(a)-15(c)), dual $\mathrm{PI}+\mathrm{C}$ controller without DC-link voltage prediction (Figs. 15(d)-15(f)), dual PI+C controller with DC-link voltage prediction (Figs. 15(g)-15(i)), and dual PI+Res2 controller (Figs. 15(j)-15(1)).

From Fig. 15(c), when the system operates with a simple dual PI controller that does not compensate for the module DC-link ripple voltages, the second-order harmonic in the circulating current is substantial with an amplitude of about $1 \mathrm{~A}$. With the dual $\mathrm{PI}+\mathrm{C}$ control strategy, this magnitude reduces to about $0.25 \mathrm{~A}$ (Fig. 15(f)), with a further reduction to only $0.1 \mathrm{~A}$ (Fig. 15(i)) when prediction of the sub-module DC-link voltages is included in the calculation.

In contrast, from Fig. 15(1), the dual PI+Res2 controller shows almost perfect suppression of the second-order harmonic component as expected. However it does present a slightly increased fourth-order harmonic because its resonant term only addresses the second-order harmonic, while the wideband dual $\mathrm{PI}+\mathrm{C}$ controller takes all low-order harmonics into account.

The slight differences between the simulation and experimental waveforms in Figs. 15(a)-15(1) are caused by simulation/experiment parameter mismatch and the inability of the PSIM model to account for parameter frequency dependence.

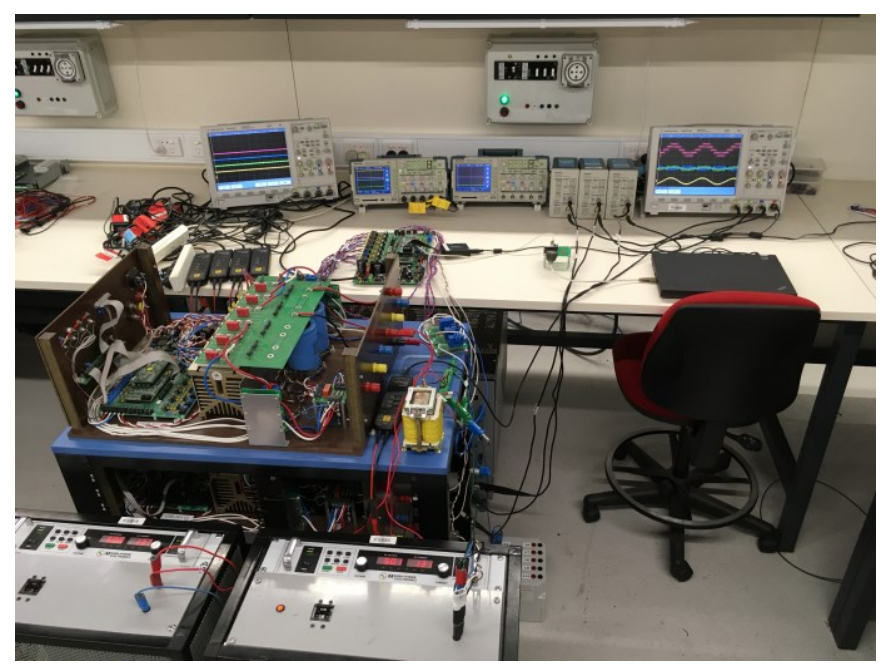

Fig. 14. The Experimental setup.
TABLE II

PROTOTYPE AND CONTROLLER PARAMETERS

\begin{tabular}{lcc}
\hline \multicolumn{1}{c}{ Description } & Symbol & Value \\
\hline System parameters & & \\
\hline DC supply voltage & $U_{d c}$ & $100 \mathrm{~V}$ \\
Coupling-inductor & $L_{s}$ & $2 \mathrm{mH}$ \\
$\quad$ Self-inductance & $L_{m}$ & $1.9 \mathrm{mH}$ \\
$\quad$ Mutual-inductance & $L_{k}$ & $0.1 \mathrm{mH}$ \\
$\quad$ Leakage-inductance & $R_{s}$ & $0.2 \Omega$ \\
$\quad$ Individual winding-resistance & $C$ & $470 \mu \mathrm{F}$ \\
DC-link capacitor & $L_{g}$ & $6.2 \mathrm{mH}$ \\
Load inductance & $R_{g}$ & $6 \Omega$ \\
Load resistance & $f_{g}$ & $50 \mathrm{~Hz}$ \\
Load frequency & $f_{c}$ & $2 \mathrm{kHz}$ \\
Switching frequency & $f_{s}$ & $4 \mathrm{kHz}$ \\
Sampling frequency & $N$ & 2 \\
Numbers of cells per arm & $\theta$ & $0 \mathrm{rad}$ \\
PSC interleaved angle & & \\
\hline Controller parameters & $M$ & 0.8 \\
\hline Differential-mode modulation depth & & $9.2 \mathrm{~A}$ \\
Common-mode current controller & $K_{i}$ & $0.0043 \mathrm{~s}$ \\
$\quad$ Proportional gain & $\tau_{i}$ & $0.0198 \mathrm{~s}$ \\
Integral reset time & $\tau_{r}$ & $0.1 \mathrm{~V}-1$ \\
$\quad$ Resonant reset time & & $0.05 \mathrm{~s}$ \\
Averaged voltage controller & $K_{u}$ & \\
$\quad$ Proportional gain & $\tau_{u}$ & \\
Integral reset time & & \\
\hline \hline
\end{tabular}

\section{Dynamic Performance}

Fig. 16 compares the transient performance of the proposed $\mathrm{PI}+\mathrm{C}$ controller (Figs. 16(a)-(f)) against the more traditional approach of using a PI+Res2 controller (Figs. 16(g)-(1)). This figure shows simulation and experimental waveforms of the upper-/lower-arm currents, common-mode circulating current, and sub-module DC-link voltages, before and after the suppression technique is enabled at $t=0.3 \mathrm{~s}$.

Figs. 16(a)-16(f) show how steady-state operation of the $\mathrm{PI}+\mathrm{C}$ controller is quickly achieved after a single fundamental cycle. In contrast, as shown in Figs. 16(g)-16(1), the PI+Res2 controller requires over three fundamental cycles to settle after the transient. This highlights the superior dynamic capability of new feed-forward compensation approach compared to the more conventional resonant feedback technique.

Figs. 16(c), 16(f), 16(i), and 16(1) confirm that both of these approaches do not compromise the sub-module DC-link voltages natural balancing mechanism even during the transient period after the controller has been enabled. Moreover, also from these figures, both control methodologies slightly increase the ripple magnitude of sub-module DC-link voltages when the low-order circulating current suppression technique is enabled. This is expected as a harmonic circulating current typically attenuates the ripple magnitude of the sub-module DC-link voltages [10].

\section{Operation under V/f Control}

Fig. 17 shows the dynamic performance of the $\mathrm{PI}+\mathrm{C}$ controller for a linear change in magnitude and frequency of the differential-mode modulation command signal (modulation depth and fundamental frequency decreasing from 0.8 to 0.64 and $50 \mathrm{~Hz}$ to $40 \mathrm{~Hz}$, respectively), initiating at $t=0.5 \mathrm{~s}$. This emulates the constant $V / f$ operation typically adopted in variable speed drives for induction motors, and illustrates the ability of the proposed feed-forward suppression technique to operate 


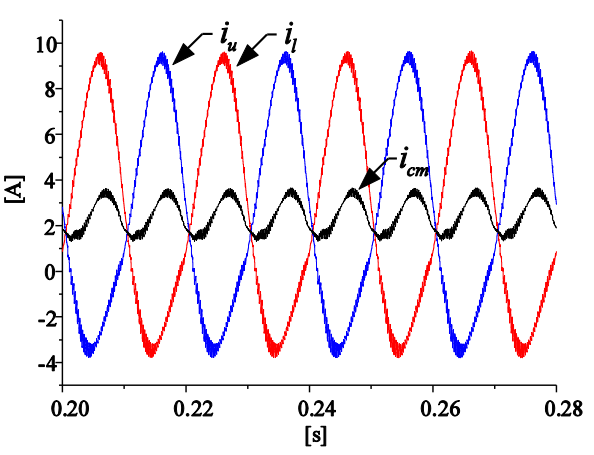

(a)

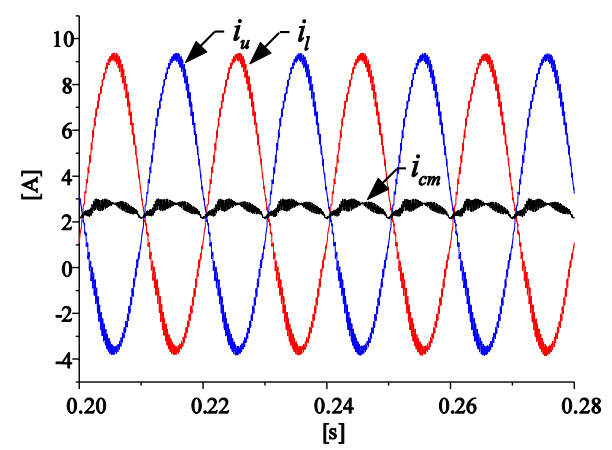

(d)

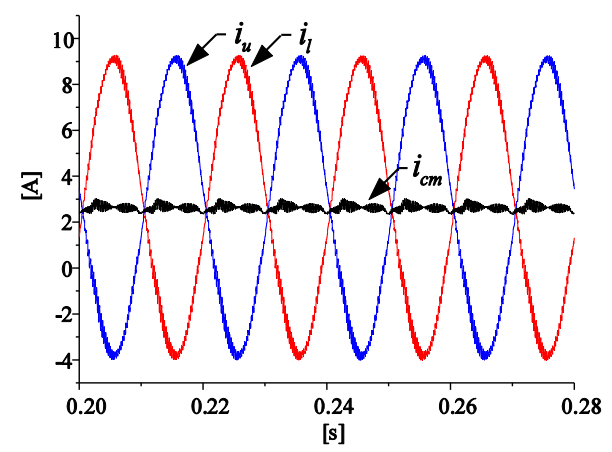

(g)

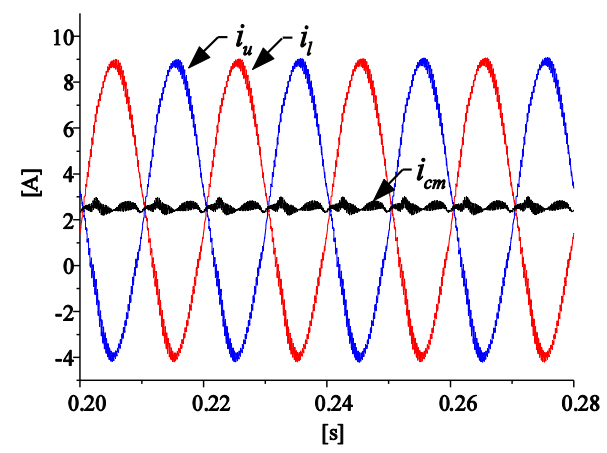

(j)

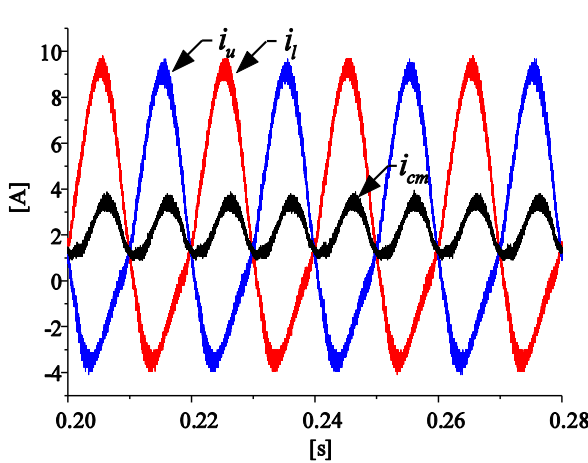

(b)

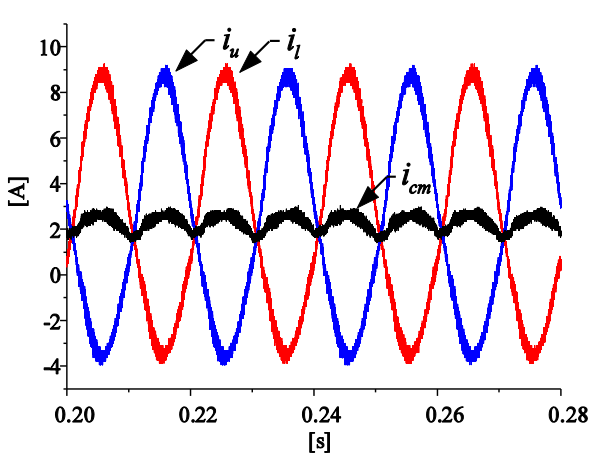

(e)

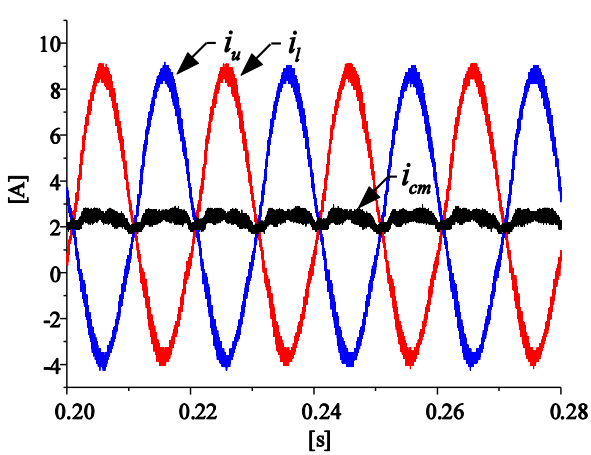

(h)

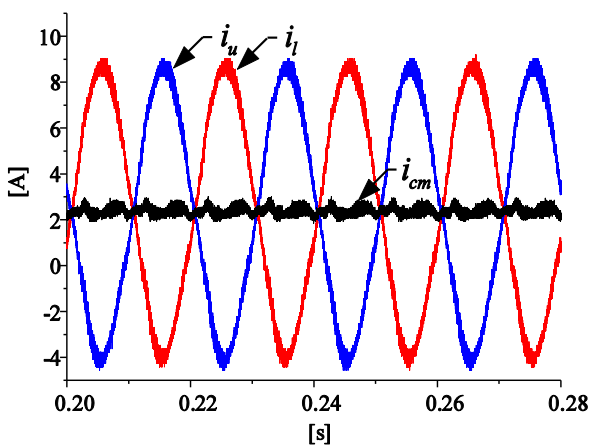

(k)

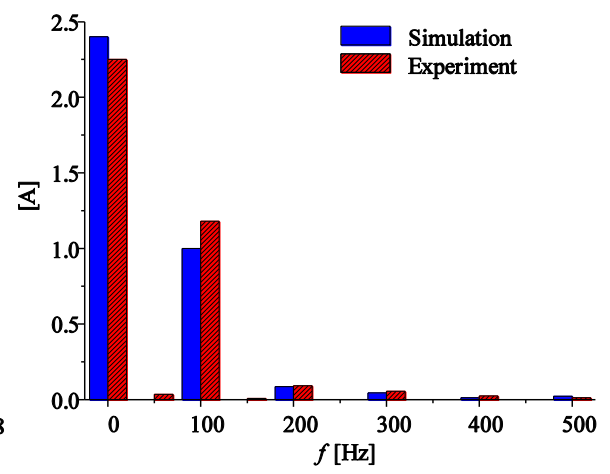

(c)

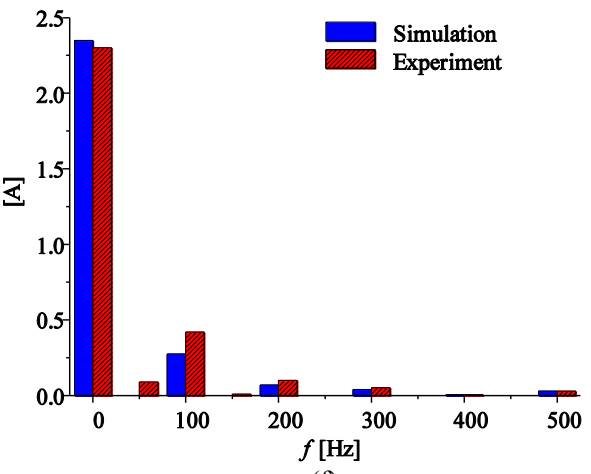

(f)

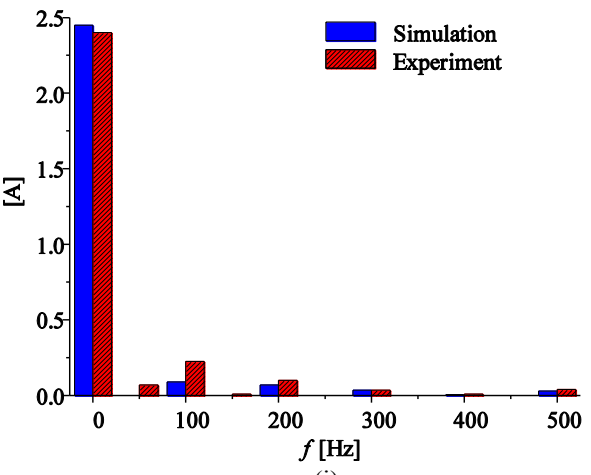

(i)

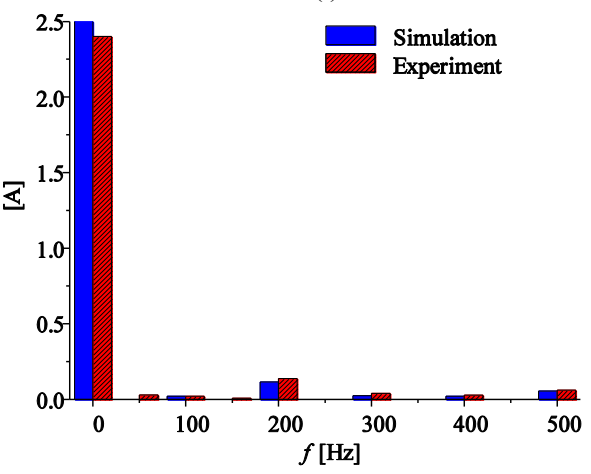

(1)

Fig. 15. Steady-state response of arm currents $i_{u}, i_{l}$ and circulating current (common-mode current $i_{c m}$ ): (a, b) Simulation and experimental waveforms, dual PI controller, (c) spectrum of circulating current $i_{c m}$, dual PI controller, (d, e) Simulation and experimental waveforms, dual PI+C controller without DC-link voltage prediction, (f) spectrum of circulating current $i_{c m}$, dual PI+C controller without DC-link voltage prediction, (g, h) Simulation and experimental waveforms, dual $\mathrm{PI}+\mathrm{C}$ controller with DC-link voltage prediction, (i) spectrum of circulating current $i_{c m}$, dual PI+C controller with DC-link voltage prediction, (j, k) Simulation and experimental waveforms, dual PI+Res 2 controller, and (1) spectrum of circulating current $i_{c m}$, dual PI+Res 2 controller.

under variable fundamental frequency without requiring any dynamic controller gain re-tuning. Also, from Figs. 17(c) and $17(\mathrm{f})$, it can be seen how the sub-module DC-link voltages remain naturally balanced throughout the whole dynamic converter operation as expected. 


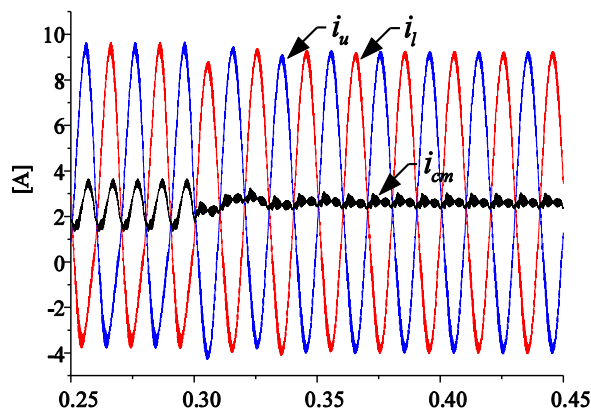

(a)

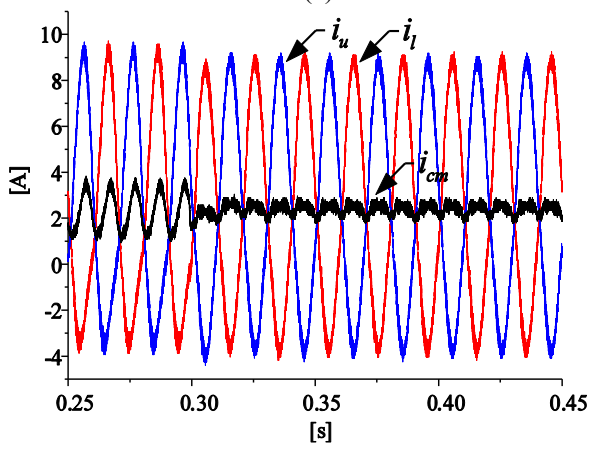

(d)

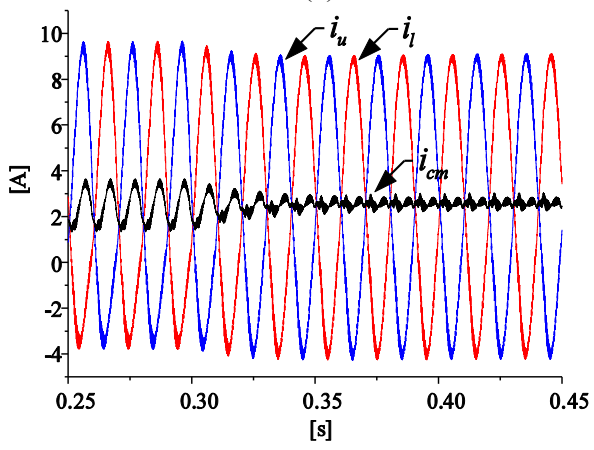

(g)

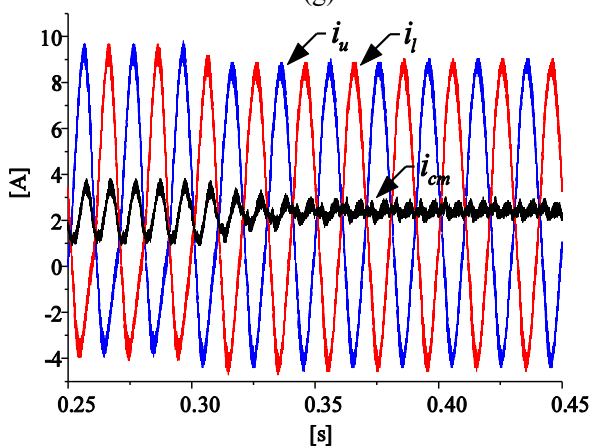

(j)

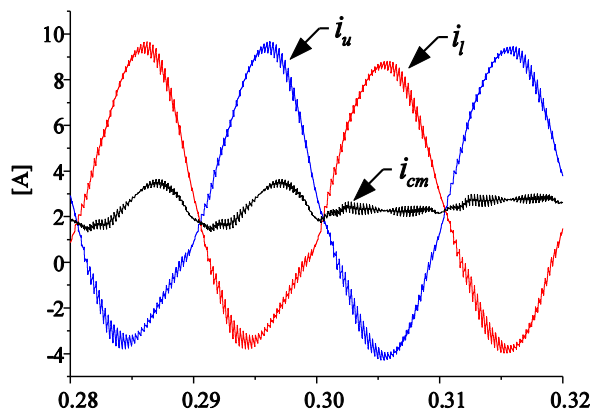

[s]

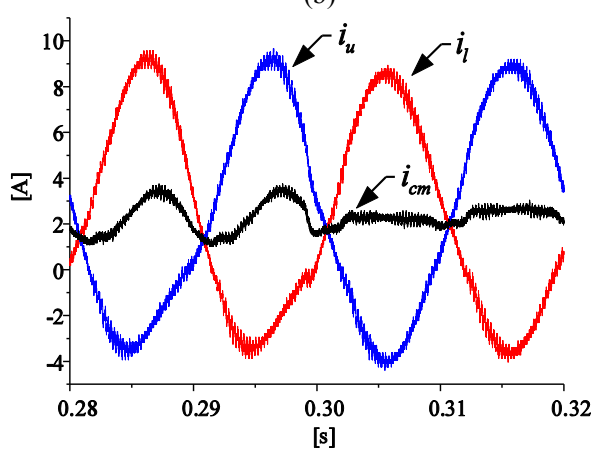

(e)

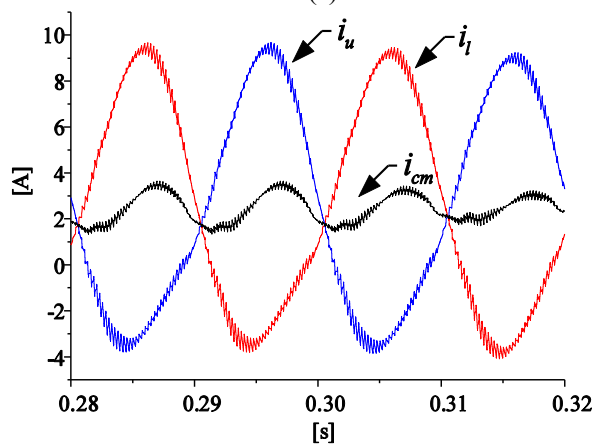

(h)

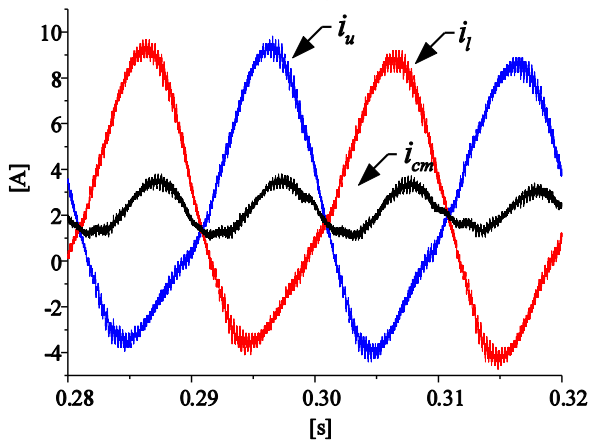

(k)

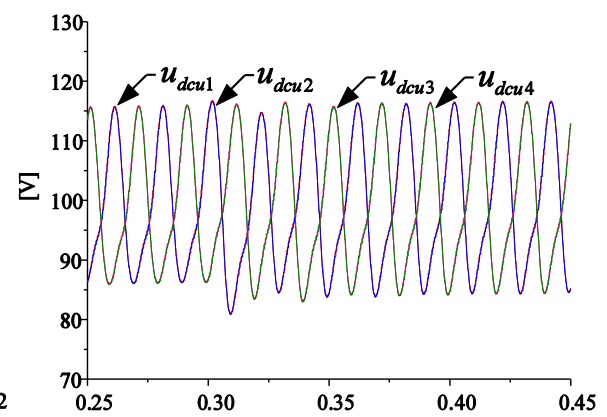

(c)

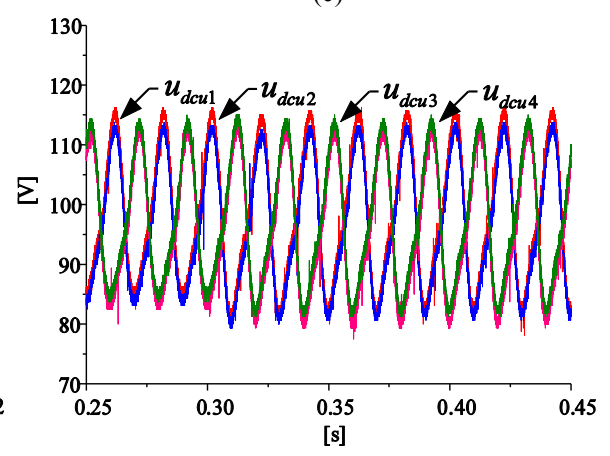

(f)

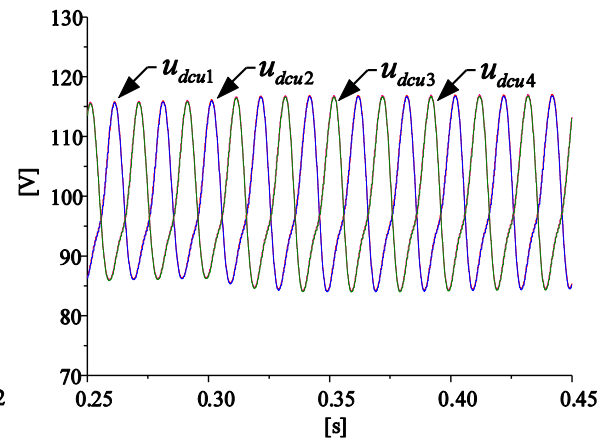

(i)

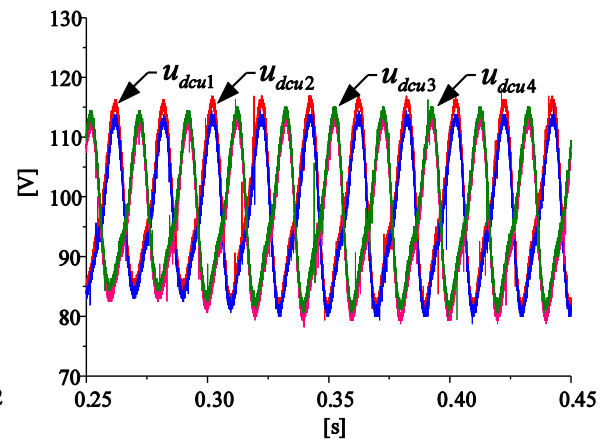

(1)

Fig. 16. Dynamic response of dual PI $+\mathrm{C}$ and dual PI+Res2 controllers: (a) Simulation waveforms of arm currents and common-mode current, dual PI $+\mathrm{C}$ controller, (b) Zoom of (a) for $t \in[0.28,0.32] \mathrm{s}$, (c) Simulation waveforms of sub-module DC-link voltages, dual PI+C controller, (d) Experimental waveforms of arm currents and common-mode current, dual PI+C controller, (e) Zoom of (d) for $t \in[0.28$, 0.32] s, (f) Experimental waveforms of sub-module DC-link voltages, dual $\mathrm{PI}+\mathrm{C}$ controller, (g) Simulation waveforms of arm currents and common-mode current, dual PI+Res2 controller, (h) Zoom of (g) for $t \in[0.28$, 0.32] s, (i) Simulation waveforms of sub-module DC-link voltages, dual PI+Res2 controller, (j) Experimental waveforms of arm currents and common-mode current, dual PI+Res2 controller, (k) Zoom of (j) for $t \in[0.28,0.32] \mathrm{s}$, and (1) Experimental waveforms of sub-module DC-link voltages, dual PI+Res2 controller.

\section{E. Operation in a Multi-frequency AC System}

The efficacy of the $\mathrm{PI}+\mathrm{C}$ feed-forward approach in suppressing multiple low-order harmonics in the circulating current is demonstrated by commanding a differential-mode modulation signal that contains an additional fifth-order harmonic component (in-phase with the fundamental component but $79 \%$ smaller in magnitude), as shown in Fig. 18. The low-order harmonic suppression process is enabled at $t=0.6 \mathrm{~s}$.

The performance of the feed-forward controller for single and multiple frequency AC systems can be assessed by comparing Figs. 16(a)-(f) and Fig. 18. From these figures, for both scenarios the initiating transient takes about one fundamental cycle to settle, with the circulating current then reducing to 


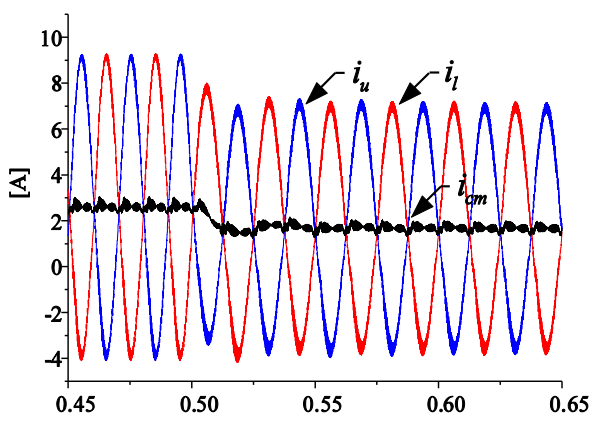

[s]
(a)

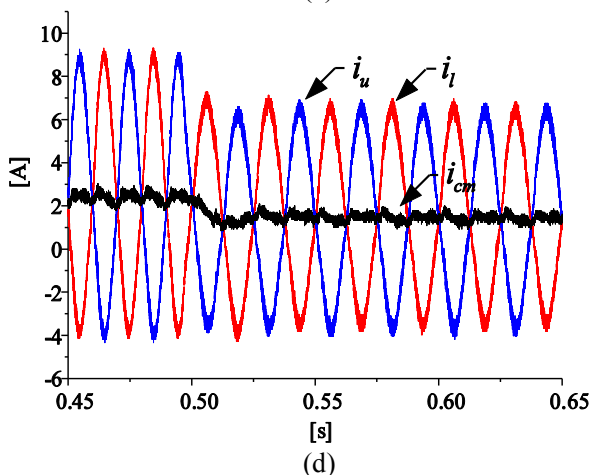

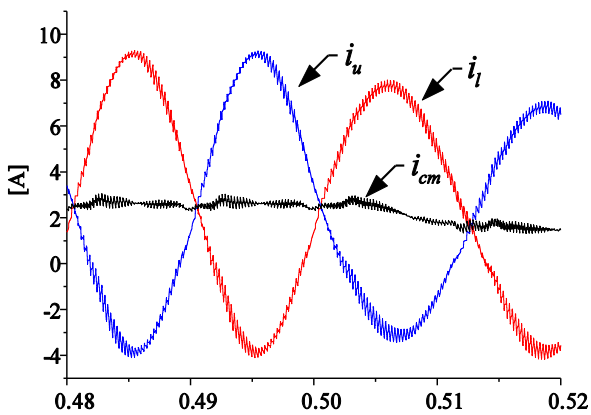

[s]
(b)

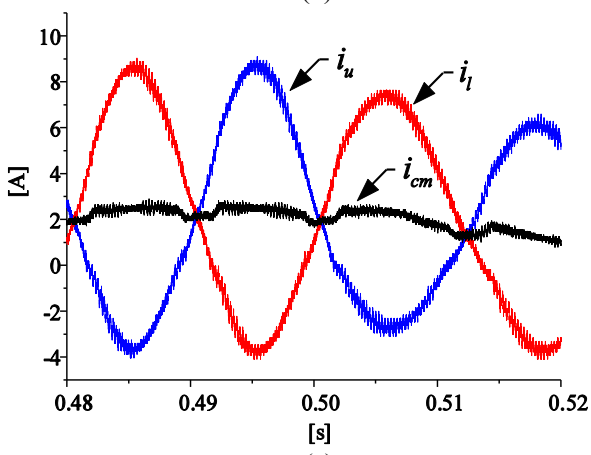

(e)

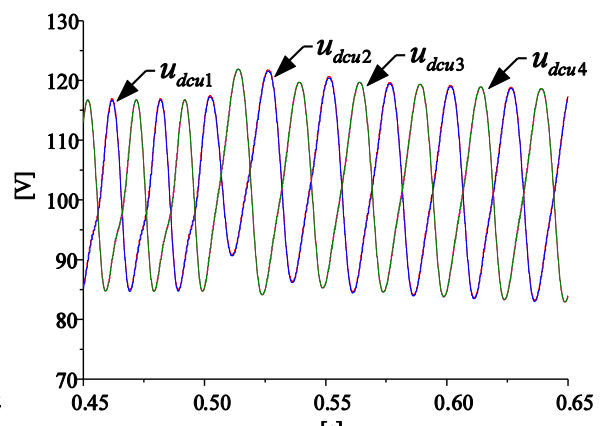

(c)

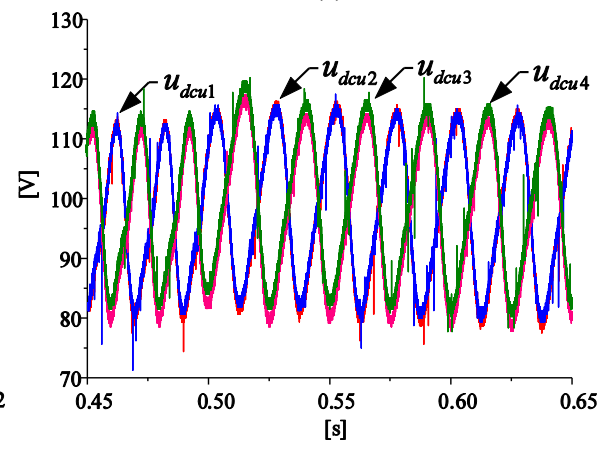

(f)

Fig. 17. Dynamic response of dual PI+C controller operating with $V / f$ control: (a) Simulation waveforms of arm currents and common-mode current, (b) Zoom of (a) for $t \in[0.48,0.52] \mathrm{s}$, (c) Simulation waveforms of sub-module DC-link voltages, (d) Experimental waveforms of arm currents and common-mode current, (e) Zoom of (d) for $t \in[0.48,0.52] \mathrm{s}$, and (f) Experimental waveforms of sub-module DC-link voltages.

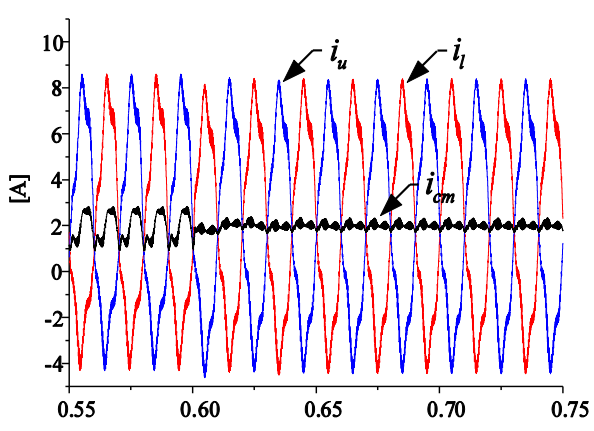

(a)

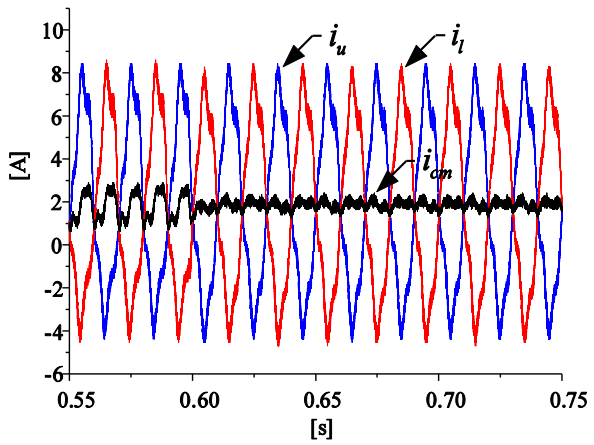

(d)

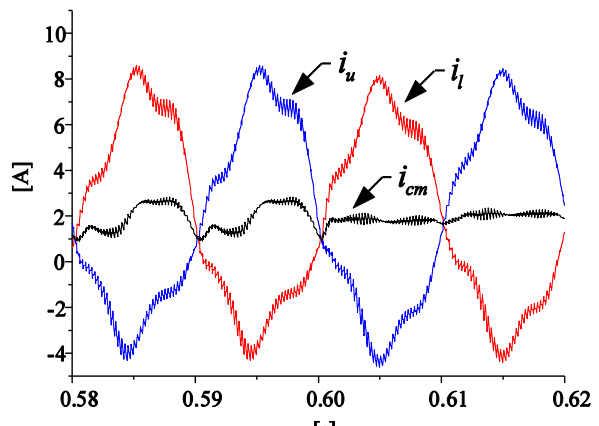

(b)

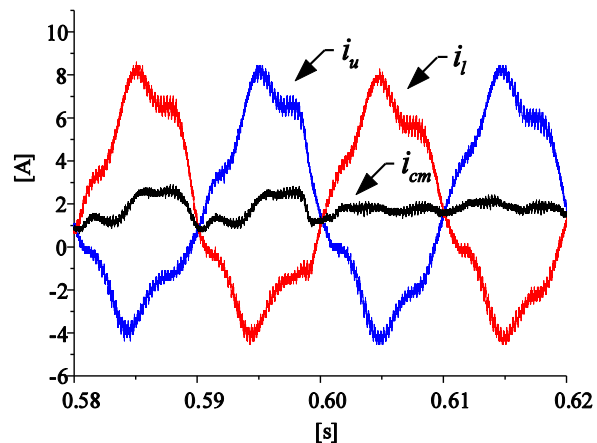

(e)

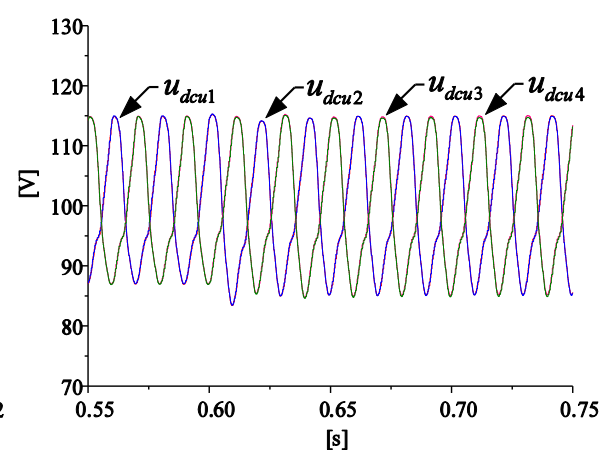

(c)

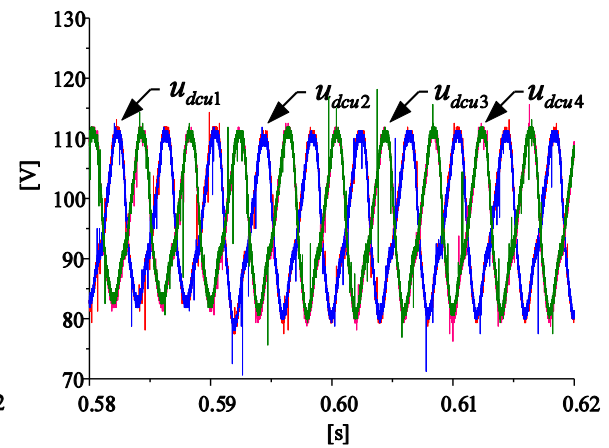

(f)

Fig. 18. Dynamic response of dual PI $+\mathrm{C}$ controller operating in a multiple-frequency AC system: (a) Simulation waveforms of arm currents and common-mode current, (b) Zoom of (a) for $t \in[0.58,0.62] \mathrm{s}$, (c) Simulation waveforms of sub-module DC-link voltages, (d) Experimental waveforms of arm currents and common-mode current, (e) Zoom of (d) for $t \in[0.58,0.62] \mathrm{s}$, and (f) Experimental waveforms of sub-module DC-link voltages.

similar small levels of low-order harmonics in the steady-state. These results confirm the direct applicability of the feed-forward suppression technique to multiple output frequency systems, since it does not require additional resonant terms to deal individually with the various even harmonics that are created in the DC circulating current from these output frequencies.

\section{CONCLUSION}

This paper has presented a new feed-forward DC-link voltage compensation technique $(\mathrm{PI}+\mathrm{C})$ for suppressing low-order circulating current harmonics in a MMC. Using an improved 
common- and differential-mode average MMC model, the interactions between the sub-module DC-link bus voltage ripple and the sub-module modulation commands that cause circulating current ripple are identified, and are used to create a common-mode modulation augmentation term that compensates for these interactions. The approach also maintains the natural balance capability of a MMC by controlling the upper and lower arms together. While the direct feed-forward idea derives partly from the concept of a classical PI $+\mathrm{R}$ closed-loop controller, it achieves a significantly improved transient response and a wider frequency band response compared to this strategy, which makes it particularly attractive for systems with fundamental output frequency variations or multiple AC output frequencies. The validity and effectiveness of the new method has been confirmed through extensive simulation and experimental results.

\section{REFERENCES}

[1] A. Lesnicar and R. Marquardt, "An innovative modular multilevel converter topology suitable for a wide power range," in Proc. IEEE Bologna Power Tech. Conf., Jun. 2003, vol. 3, p. 6.

[2] H. Akagi, "Classification, terminology, and application of the modular multilevel cascade converter (MMCC)," IEEE Trans. Power Electron., vol. 26, no. 11, pp. 3119-3130, Nov. 2011.

[3] M. A. Perez, S. Bernet, J. Rodriguez, S. Kouro and R. Lizana, "Circuit Topologies, modeling, control schemes, and applications of modular multilevel converters," IEEE Trans. Power Electron., vol. 30, no. 1, pp. 4-17, Jan. 2015.

[4] M. Hagiwara, R. Maeda and H. Akagi, "Negative-sequence reactive-power control by a PWM STATCOM based on a modular multilevel cascade converter (MMCC-SDBC)," IEEE Trans. Ind. Appl., vol. 48, no. 2, pp. 720-729, Mar./Apr. 2012.

[5] Y. Okazaki, M. Hagiwara, and H. Akagi, "A speed-sensorless start-up method of an induction motor driven by a modular multilevel cascade inverter," IEEE Trans. Ind. Appl., vol. 50, no. 4, pp. 2671-2680, Jul./Aug. 2015.

[6] T. Soong and P. W. Lehn, "Internal power flow of a modular multilevel converter with distributed energy resources," IEEE J. Emer. Sel. Topics Power Electron., vol. 2, no. 2, pp. 249-263, Jun. 2014.

[7] M. Vasiladiotis, N. Cherix and A. Rufer, "Accurate capacitor voltage ripple estimation and current control considerations for grid-connected modular multilevel converters," IEEE Trans. Power Electron., vol. 29, no. 9, pp. 4568-4579, Sep. 2014.

[8] R. Darus, J. Pou, S. Ceballos, J. Zaragoza, G. Konstantinou and V. G. Agelidis, "Optimal injection of harmonics in circulating currents of modular multilevel converters for capacitor voltage ripple minimization," in Proc. IEEE ECCE Asia Downunder, 2013, pp. 318-324.

[9] B. Li, Y. Zhang, G. Wang, W. Sun, D. Xu, W. Wang, "A modified modular multilevel converter with reduced capacitor voltage fluctuation," IEEE Trans. Ind. Electron., vol. 62, no. 10, pp. 6108-6119, Oct. 2015.

[10] J. Pou, S. Ceballos, G. Konstantinou, V. G. Agelidis, R. Picas and J. Zaragoza, "Circulating current injection methods based on instantaneous information for the modular multilevel converter," IEEE Trans. Ind. Electron., vol. 62, no. 2, pp. 777-788, Feb. 2015.

[11] B. P. McGrath, C. A. Teixeira and D. G. Holmes, "Optimised phase disposition (PD) modulation of a modular multilevel converter using a state machine decoder," in Proc. IEEE Energy Convers. Congr. Expo., 2015, pp. 6368-6375.

[12] M. Hagiwara and H. Akagi, "Control and experiment of pulsewidth-modulated modular multilevel converters," IEEE Trans. Power Electron., vol. 24, no. 7, pp. 1737-1746, Jul. 2009.

[13] M. Hagiwara, R. Maeda and H. Akagi, "Control and analysis of the modular multilevel cascade converter based on double-star chopper-cells (MMCC-DSCC)," IEEE Trans. Power Electron., vol. 26, no. 6, pp. 1649-1658, Jun. 2011.

[14] K. Ilves, L. Harnefors, S. Norrga and H. Nee, "Analysis and operation of modular multilevel converters with phase-shifted carrier PWM," IEEE Trans. Power Electron., vol. 30, no. 1, pp. 268-283, Jan. 2015.

[15] R. Darus, J. Pou, G. Konstantinou, S. Ceballos and V. G. Agelidis, "Circulating current control and evaluation of carrier dispositions in modular multilevel converters," in Proc. IEEE ECCE Asia Downunder, 2013, pp. 332-338.

[16] B. Li, R. Yang, D. Xu, G. Wang, W. Wang and D. Xu, "Analysis of the phase-shifted carrier modulation for modular multilevel converters," IEEE Trans. Power Electron., vol. 30, no. 7, pp. 297-310, Jul. 2015.

[17] S. Debnath, J. Qin, B. Bahrani, M. Saeedifard and P. Barbosa, "Operation, control, and applications of the modular multilevel converter: a review," IEEE Trans. Power Electron., vol. 30, no. 1, pp. 37-53, Jan. 2015.

[18] Q. Song, W. Liu, X. Li, H. Rao, S. Xu and L. Li, "A steady-state analysis method for a modular multilevel converters," IEEE Trans. Power Electron., vol. 28, no. 8, pp. 3702-3713, Aug. 2013.

[19] K. Ilves, A. Antonopoulos, S. Norrga and H. Nee, "Steady-state analysis of interaction between harmonic components of arm and line quantities of modular multilevel converters," IEEE Trans. Power Electron., vol. 27, no. 1, pp. 57-68, Jan. 2012.

[20] Q. Tu, Z. Xu and L. Xu, "Reduced switching-frequency modulation and circulating current suppression for modular multilevel converters," IEEE Trans. Power Del., vol. 26, no. 3, pp. 2009-2017, Jul. 2011.

[21] B. Bahrani, S. Debnath and M. Saeedifard, "Circulating current suppression of the modular multilevel converter in a double-frequency rotating reference frame," IEEE Trans. Power Electron., vol. 31, no. 1, pp. 783792, Jan. 2016.

[22] J. Moon, C. Kim, J. Park, D. Kang and J. Kim, "Circulating current control in MMC under the unbalanced voltage," IEEE Trans. Power Del., vol. 28, no. 3, pp. 1952-1959, Jul. 2013.

[23] J. Moon, J. Park, D. Kang and J. Kim, "A control method of HVDC-modular multilevel converter based on arm current under the unbalanced voltage condition," IEEE Trans. Power Del., vol. 30, no. 2, pp. 529-536, Apr. 2015.

[24] Y. Zhou, D. Jiang, J. Guo, P. Hu and Y. Liang, "Analysis and control of modular multilevel converters under unbalanced conditions," IEEE Trans. Power Del., vol. 28, no. 4, pp. 1986-1995, Oct. 2013.

[25] S. Li, X. Wang, Z. Yao, T. Li and Z. Peng, "Circulating current suppressing strategy for MMC-HVDC based on nonideal proportional resonant controllers under unbalanced grid conditions," IEEE Trans. Power Electron., vol. 30, no. 1, pp. 387-397, Jan. 2015.

[26] R. Mishra and A. Shukla, "A proportional resonator-based control scheme to suppress AC components in circulating current of modulator multilevel converter," in Proc. IEEE 39th Annu. Conf. Ind. Electron. Soc., Vienna, Austria, 2013, pp. 6170-6175.

[27] Z. Li, P. Wang, Z. Chu, H. Zhu, Y. Luo and Y. Li, "An inner current suppressing method for modular multilevel converters," IEEE Trans. Power Electron., vol. 28, no. 11, pp. 4873-4879, Nov. 2013.

[28] X. She, A. Huang, X. Ni and R. Burgos, "AC circulating currents suppression in modular multilevel converter," in Proc. IEEE 38th Annu. Conf. Ind. Electron. Soc., ÉTS Montréal, QC, Canada, Oct. 25-28, 2012, pp. 190-194.

[29] X. She and A. Huang, "Circulating current control of double-star chopper-cell modular multilevel converter for HVDC system," in Proc. IEEE 38th Annu. Conf. Ind. Electron. Soc., ÉTS Montréal, QC, Canada, Oct. 25-28, 2012, pp. 1234-1239.

[30] M. Zhang, L. Huang, W. Yao and Z. Lu, "Circulating harmonic current elimination of a CPS-PWM-based modular multilevel converter with a plug-in repetitive controller," IEEE Trans. Power Electron., vol. 29, no. 4, pp. 2083-2097, Apr. 2014.

[31] L. He, K. Zhang, J. Xiong and S. Fan, "A repetitive control scheme for harmonic suppression of circulating current in modular multilevel con verters," IEEE Trans. Power Electron., vol. 30, no. 1, pp. 471-481, Jan. 2015.

[32] A. Antonopoulos, L. Angquist, and H. Nee, "On dynamics and voltage control of the modular multilevel converter," in Proc. Eur. Conf. Power Electron. Appl., Sep. 2009, pp. 1-10.

[33] L. Harnefors, A. Antonopoulos, S. Norrga, L. Angquist and H. Nee, "Dynamic analysis of modular multilevel converters," IEEE Trans. Ind. Electron., vol. 60, no. 7, pp. 2526-2537, Jul. 2013.

[34] L. Angquist, A. Antonopoulos, D. Siemaszko, K. Ilves, M. Vasiladiotis and $\mathrm{H}$. Nee, "Open-loop control of modular multilevel converters using estimation of stored energy," IEEE Trans. Ind. Appl., vol. 47, no. 6, pp. 2516-2524, Nov./Dec. 2011.

[35] A. Antonopoulos, L. Angquist ,L. Harnefors, , K. Ilves, and H. Nee, "Global asymptotic stability of modular multilevel converters," IEEE Trans. Ind. Electron., vol. 61, no. 2, pp. 603-612, Feb. 2014.

[36] L. Harnefors, A. Antonopoulos, K. Ilves, and H. Nee, "Global asymptotic stability of current-controlled modular multilevel converters," IEEE Trans. Power Electron., vol. 30, no. 1, pp. 249-258, Jan. 2015. 
[37] D.G. Holmes, and T. Lipo, Pulse Width Modulation for Power Converters: Principles and Practice, New York: IEEE Press, 2003.

[38] W. Merwe, P. Hokayem and L. Stepanova, "Analysis of the $N$-cell single phase MMC natural balancing mechanism," IEEE J. Emer. Sel. Topics Power Electron., vol. 2, no. 4, pp. 1149-1158, Dec. 2014.

[39] D. G. Holmes, T. A. Lipo, B. P. McGrath and W. Y. Kong, "Optimized design of stationary frame three phase AC current regulators," IEEE Trans. Power Electron., vol. 24, no. 11, pp. 2417-2426, Nov. 2009.

[40] C. A. Teixeira, B. P. McGrath and D. G. Holmes, "Closed-loop current control of multilevel converters formed by parallel complementary unidirectional phase legs," IEEE Trans. Ind. Appl., vol. 51, no. 2, pp. 16211629, Mar./Apr. 2015.

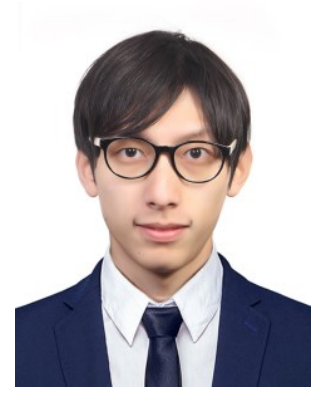

Yichao Sun (S'13-M'17) received the B.S. degree in Electrical Engineering (2010) from Southeast University, Nanjing, China, where he is currently working toward the Ph.D. degree at the School of Electrical Engineering.

From February 2015 to August 2016, Mr. Sun was a Visiting Scholar in the Power Electronics Group (PEG) at RMIT University, Melbourne, Australia. His research interests include the modulation and control of power electronic converters, with a particular emphasis on multilevel converters.

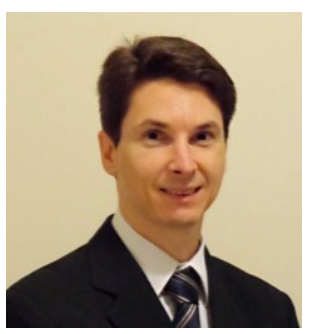

Carlos Alberto Teixeira (S'11-M'14) received the B.S. and M.S. degrees in Electrical Engineering (2000 and 2008, respectively) from Santa Catarina State University (UDESC), Joinville, Brazil, and the Ph.D. degree in Electrical and Computer Engineering (2014) from RMIT University, Melbourne, Australia.

Dr Teixeira is with the School of Electrical and Computer Engineering at RMIT University in Melbourne Australia. From 2000 to 2008, he was a Researcher at Whirlpool Corporation, Joinville, Brazil. From 1995 to 1999, he was a member of the Tutorial Education Program (PET/SESu) in Electrical Engineering of UDESC. His research interests include the modulation and control of power electronic converters and the modeling and control of discrete event systems. He has published over twenty conference and journal articles and has coauthored two international patents.

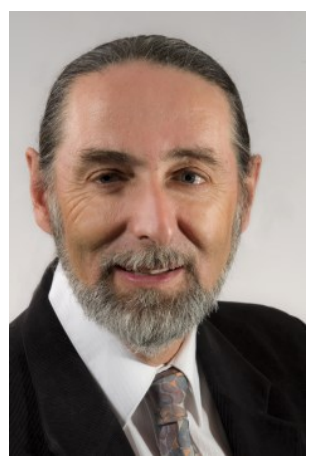

Donald Grahame Holmes (M'88-SM'03-F'13) received the B.S. degree and the M.S. degree in power systems engineering from the University of Melbourne, Melbourne, Australia, in 1974 and 1979, respectively, and the Ph.D. degree in PWM theory for power electronic converters from Monash University, Clayton, Australia, in 1998.

In 1984, he joined Monash University, where he established and directed the Power Electronics Group for over 25 years. In 2010 he moved to RMIT University to take up a professorial chair in Smart Energy. Professor Holmes' research interests include fundamental modulation theory, current regulators for drive systems and PWM rectifiers, active filter systems, resonant converters, current-source inverters and multilevel converters. He has been an IEEE member since 1987, has published over 250 conference and transaction papers, and regularly reviews papers for all major IEEE transactions in his area. He has also co-authored a major reference textbook on PWM theory with Prof.
Thomas Lipo of the University of Wisconsin-Madison, Madison, WI, USA.

Prof. Holmes is a member of the Industrial Power Converter and the Industrial Drive Committees of the IEEE Industrial Applications Society, and has held a number of positions on the Adcom of the IEEE Power Electronics Society over many years.

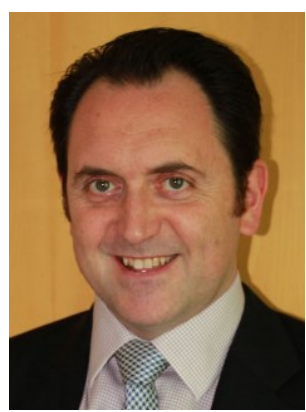

Brendan McGrath (M'99-SM'16) received the $\mathrm{BE}$ degree in Electrical and Computer Systems Engineering (1997), the BSc degree in Applied Mathematics and Physics (1997), and the Ph.D. degree (2003) from Monash University, Victoria, Australia.

Assoc. Prof. McGrath is with the school of electrical and computer engineering at RMIT university in Melbourne Australia. His research interests include the modulation and control of power electronic converters, particularly multilevel systems. He has published over 100 journal and conference articles, and in 2004 was awarded the Douglas Lampard research medal from Monash University for his Ph.D. thesis.

Assoc. Prof. McGrath is a member of the IEEE Power Electronics, Industry Applications and Industrial Electronics Societies, and is an associate editor for the IEEE Transactions on Power Electronics.

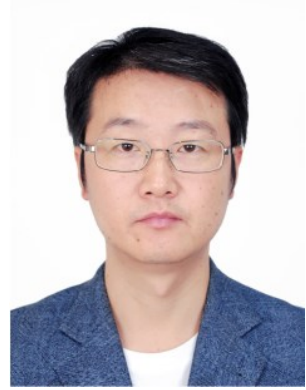

Jianfeng Zhao received the B.S. degree from Huainan Mining Institute, Huainan, China, the M.S. degree from the Nanjing University of Aeronautics and Astronautics, Nanjing, China, and the Ph.D. degree from Southeast University, Nanjing, in 1995, 1998, and 2001, respectively, all in electrical engineering.

In 2001, he joined the Faculty of the School of Electrical Engineering, Southeast University, where since 2008, he has been a Professor and has been engaged in teaching and research in the field of high power electronics. Since 2014, he has also been serving as the Dean of the School of Electrical Engineering, Southeast University. He has published more than 100 technical papers. He holds more than 20 China patents. His main research interests include utility applications of power electronics in smart grid such as solid-state transformer, active filters for power conditioning, flexible ac-transmission system devices, multilevel ac-motor drives, and efficient energy utilization.

Dr. Zhao has been a member of the Technical Committee on standard voltages, current ratings and frequencies of China since 2010. He has also been a member of All-China Youth Federation since 2010. 